\title{
Design of Laser Welding Parameters for Joining Ti Grade 2 and AW 5754 Aluminium Alloys Using Numerical Simulation
}

\author{
Mária Behúlová, Eva Babalová, and Miroslav Sahul \\ Faculty of Materials Science and Technology in Trnava, Slovak University of Technology in Bratislava, \\ Ulica Jána Bottu č. 2781/25, 91724 Trnava, Slovakia \\ Correspondence should be addressed to Mária Behúlová; maria.behulova@stuba.sk
}

Received 17 April 2017; Revised 8 August 2017; Accepted 29 August 2017; Published 16 October 2017

Academic Editor: Ying Li

Copyright (C) 2017 Mária Behúlová et al. This is an open access article distributed under the Creative Commons Attribution License, which permits unrestricted use, distribution, and reproduction in any medium, provided the original work is properly cited.

Joining of dissimilar Al-Ti alloys is very interesting from the point of view of weight reduction of components and structures in automotive or aerospace industries. In the dependence on cooling rate and chemical composition, rapid solidification of Al-Ti alloys during laser welding can lead to the formation of metastable phases and brittle intermetallic compounds that generally reduce the quality of produced weld joints. The paper deals with design and testing of welding parameters for preparation of weld joints of two sheets with different thicknesses from titanium Grade 2 and AW 5754 aluminium alloy. Temperature fields developed during the formation of Al-Ti butt joints were investigated by numerical simulation in ANSYS software. The influence of laser welding parameters including the laser power and laser beam offset on the temperature distribution and weld joint formation was studied. The results of numerical simulation were verified by experimental temperature measurement during laser beam welding applying the TruDisk 4002 disk laser. The microstructure of produced weld joints was assessed by light microscopy and scanning electron microscopy. EDX analysis was applied to determine the change in chemical composition across weld joints. Mechanical properties of weld joints were evaluated using tensile tests and Vickers microhardness measurements.

\section{Introduction}

The specific properties of different materials are jointly utilized to achieve the required product performance. This trend is reported for several industries including automotive, aircraft, aeronautic, or marine applications. For example, the light-weight construction of the Boeing 787 Dreamliner consists of $50 \%$ composite materials (the primary material of the airframe structure), $20 \%$ aluminium, $15 \%$ titanium, $10 \%$ steel, and $5 \%$ other materials [1]. Aluminium is used for the wing and tail leading edges; titanium is applied mainly on engines and fasteners.

Joining two dissimilar metals is often difficult due to the distinct material properties and chemical reactions between different materials which can lead to the formation of intermetallic compounds (IMC) at the metals interface during the welding process. The presence of IMC in weld joints generally degrades the mechanical properties and quality of the welds. Therefore, the effort during the design of technology for welding of dissimilar material is aimed at elimination of IMC formation. The thickness of the IMC layer depends on the temperature profile generated by the heat source exploited for welding and the heat flux distribution across the interface. However, the thermal fields are also responsible for geometry of the fusion zone and thus the dimension of the bonding area [2].

The successful joining of aluminium to titanium requires the reduction in thickness of potentially brittle intermetallic zones such as $\mathrm{Ti}_{3} \mathrm{Al}, \mathrm{TiAl}$, and $\mathrm{TiAl}_{3}$. Therefore, it is difficult to join the Al-Ti compound structures by means of conventional fusion welding [3]. Laser welding with its high energy density alleviates these problems and provides additional benefits [4]. The small size and accuracy of the laser beam provide the possibility to control the microstructure development. Rapid solidification results in a narrow heat-affected zone (HAZ) and less grain growth. Formation of a brittle layer of IMC can occur, although its thickness is smaller than that in conventional arc welding, for example [5]. Moreover, laser welding allows obtaining thin and high precision welds and reducing thermal distortion. Small interaction zone 
TABLE 1: Chemical composition of titanium Grade 2.

\begin{tabular}{lcccccc}
\hline Element & $\mathrm{Fe}$ & $\mathrm{C}$ & $\mathrm{O}$ & $\mathrm{H}$ & $\mathrm{N}$ & $\mathrm{Ti}$ \\
\hline wt.\% & 0.3 & 0.1 & 0.25 & 0.015 & 0.03 & Balance \\
\hline
\end{tabular}

TABLE 2: Chemical composition of AW 5754 aluminium alloy.

\begin{tabular}{lccccc}
\hline Element & $\mathrm{Mg}$ & $\mathrm{Mn}$ & $\mathrm{Fe}$ & $\mathrm{Si}$ & $\mathrm{Al}$ \\
\hline wt.\% & 2.6 to 3.2 & 0.5 & 0.4 & 0.4 & Balance \\
\hline
\end{tabular}

and high welding speed promote high thermal gradients, which are useful for local phase content optimization. So, the importance of mixing and diffusion phenomena can be reduced. In addition, the effect of mismatch on thermophysical properties of welded dissimilar materials can be eliminated by the offset of laser beam to one of the welded component. Laser offset welding was demonstrated to be a promising technique to join dissimilar metals, being capable of producing effective bonding with good tensile strength [6]. The use of higher welding speeds $\left(>4 \mathrm{~m} \cdot \mathrm{min}^{-1}\right)$ would minimize the interdiffusion between the molten materials and reduce the development of brittle intermetallic zones [7].

Modeling and numerical simulation of welding processes have been exploited with many advantages for investigation of physical principles and complex phenomena connected with joining processes [8-13]. Together with testing and inspection, numerical simulations are mutually important to understand and predict the performance of the welding processes. Moreover, the application of numerical methods and computer simulation represents one of the ways to ensure design and optimization of welding parameters. Results of computer simulation can be applied for the relatively fast and cheap evaluation of the influence of welding parameters on the quality of the weld joints and the definition of optimal process parameters for weld manufacturing [1417]. In general, numerical simulation is regarded as a valid tool and is widely applied in welding process designing [18].

In connection with numerical simulation of welding processes, the features of distribution and variation of the temperature fields are highly important. Heat propagation during the welding process essentially depends on the geometry of welded components and thermophysical properties of the materials used to make them. Another important factor is the application and modeling of a welding heat source. In case of simple shaped sources like point, line, or plane sources, it is possible to find an analytical solution for [19]. If the heat source is of more complex shape, the solution may be obtained only by numerical integration or using, for example, the FEM method [20]. Extensive literature is available on the modeling and exploitation of heat sources for different welding technologies including surface or volumetric heat source models [12, 20-27]. For numerical simulation of laser beam welding, various volumetric heat source models have been tested and applied, ranging from Gaussian ellipsoidal heat source, Goldak's double-ellipsoidal heat source, cylindrical heat source, and cone-shaped source to some of their modifications and combinations [22, 28-33].

The paper deals with the numerical simulation of temperature fields by laser beam welding of titanium Grade 2 and AW 5754 aluminium alloy using the finite-element code ANSYS. Based on the obtained results, the appropriate welding parameters were designed to realize the real experiments of the laser welding of dissimilar Ti-Al alloy sheets by the TruDisk 4002 disk laser. The quality of the prepared weld joints was evaluated by light microscopy, EDX analysis, Xray diffraction analysis, tensile testing, and microhardness measurements.

\section{Problem Description}

Laser beam welding is applied for joining two sheets from dissimilar materials and with different thicknesses. The sheet from Ti Grade 2 with the chemical composition given in Table 1 has the thickness of $2 \mathrm{~mm}$. The thickness of the sheet from AW 5754 aluminium alloy with the chemical composition given in Table 2 is $1.5 \mathrm{~mm}$. Butt joints of the samples with dimensions of $30 \mathrm{~mm} \times 75 \mathrm{~mm}$ are assumed to be produced with different laser parameters (laser power and laser offset) using the required welding speed of $10 \mathrm{~mm} \cdot \mathrm{s}^{-1}$ and no filler material. Argon gas with the maximum flow rate of $30 \mathrm{l} \cdot \mathrm{min}^{-1}$ can be used as a shielding gas to protect both weld bead and root.

In order to save time and financial costs, numerical simulation of laser beam welding of dissimilar Al-Ti alloys is implemented to study the influence of chosen welding parameters on the temperature distribution in welded sheets and to set appropriate welding parameters for experimental preparation of weld joints by the TruDisk 4002 disk laser. The welding parameters considered in numerical experiments are summarized in Table 3.

\section{Theoretical Background and Simulation Model}

Generally, numerical simulation of laser welding processes requires solution of coupled thermal-fluid and stress-strain problems involving phase transformations [32-36]. Using this approach, it is possible to evaluate the temperature fields taking into account the melt convection in the weld pool and also the deformations of welded components. In addition, the stresses during the welding process and residual stresses remaining in the welded material after the cooling of a weld to the room temperature can be predicted in order to eliminate 
TABLE 3: Welding parameters applied for numerical experiments.

\begin{tabular}{lcc}
\hline $\begin{array}{l}\text { Experimental sample } \\
\text { number }\end{array}$ & $\begin{array}{c}\text { Laser power } \\
{[\mathrm{W}]}\end{array}$ & $\begin{array}{c}\text { Laser beam offset } \\
{[\mu \mathrm{m}]}\end{array}$ \\
\hline 1 & 750 & 250 \\
2 & 800 & 250 \\
3 & 850 & 250 \\
4 & 850 & 150 \\
5 & 850 & 100 \\
6 & 850 & 50 \\
7 & 900 & 250 \\
8 & 900 & 150 \\
9 & 900 & 100 \\
10 & 950 & 250 \\
\hline
\end{tabular}

the possible cracking and failure of the weld joint. In our case, the initial numerical simulation of the laser welding was focused particularly on the analysis of temperature field and possibility to join materials with very distinct thermal properties.

Transient temperature fields developed during welding processes can be described by the heat diffusion partial differential equation in the following form [37]:

$$
\begin{aligned}
\rho c_{p} & \frac{D T}{D t} \\
= & {\left[\frac{\partial T}{\partial x}\left(\lambda_{x} \frac{\partial T}{\partial x}\right)+\frac{\partial T}{\partial y}\left(\lambda_{y} \frac{\partial T}{\partial y}\right)+\frac{\partial T}{\partial z}\left(\lambda_{z} \frac{\partial T}{\partial z}\right)\right] } \\
& +q_{v},
\end{aligned}
$$

where $T(x, y, z, t)$ is the temperature $\left[{ }^{\circ} \mathrm{C}, \mathrm{K}\right], t$ is the time $[\mathrm{s}]$, $\rho$ is the density $\left[\mathrm{kg} \cdot \mathrm{m}^{-3}\right], c_{p}$ is the specific heat $\left[\mathrm{J} \cdot \mathrm{kg}^{-1} \cdot \mathrm{K}^{-1}\right]$, $\lambda_{x}, \lambda_{y}$, and $\lambda_{z}$ are the thermal conductivities $\left[\mathrm{W} \cdot \mathrm{m}^{-1} \cdot \mathrm{K}^{-1}\right.$ ] in the $x, y$, and $z$ directions of Cartesian coordinate system, respectively, and $q_{v}$ is the volumetric density of internal heat sources $\left[\mathrm{W} \cdot \mathrm{m}^{-3}\right]$, that is, the heat generated in the unit volume of material per unit time. The expression $D T / D t$ represents the substantial derivative of temperature. To solve the heat diffusion equation (1), it is necessary to specify geometrical, physical, initial, and boundary conditions, that is, geometrical shapes and dimensions of welded components, thermophysical properties of welded materials, intensity of internal heat sources, and initial temperature distribution at the beginning of the welding process, and also the conditions and thermal effects at the interface of welded structures and environment.

Considering the problem definition, the computational domains representing the welded plates had dimensions of $30 \mathrm{~mm} \times 30 \mathrm{~mm} \times 1.5 \mathrm{~mm}$ (Al plate) and $30 \mathrm{~mm} \times 30 \mathrm{~mm} \times$ $2 \mathrm{~mm}$ (Ti plate). The 3D finite-element mesh was generated using the ANSYS finite-element software [38] according to supposed temperature gradients; that is, the mesh density was the highest in the region of the weld pool and the heat-affected zone. The eight-node three-dimensional solid elements of the type of SOLID70 were applied for the thermal

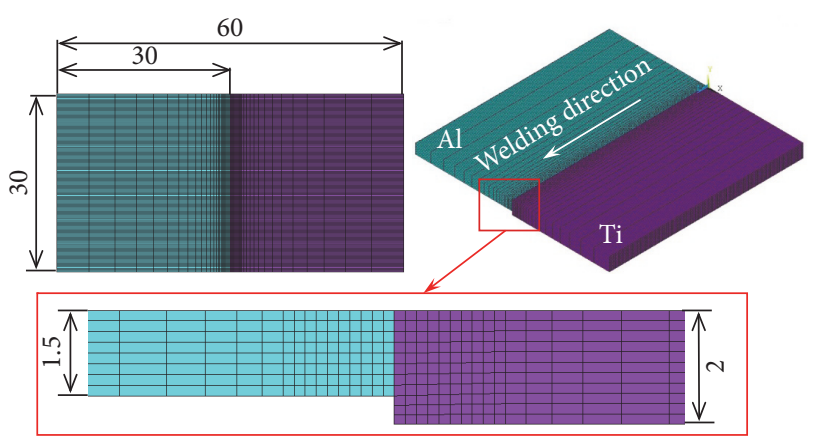

FIGURE 1: FEM model of welded sample with the detail of generated mesh.

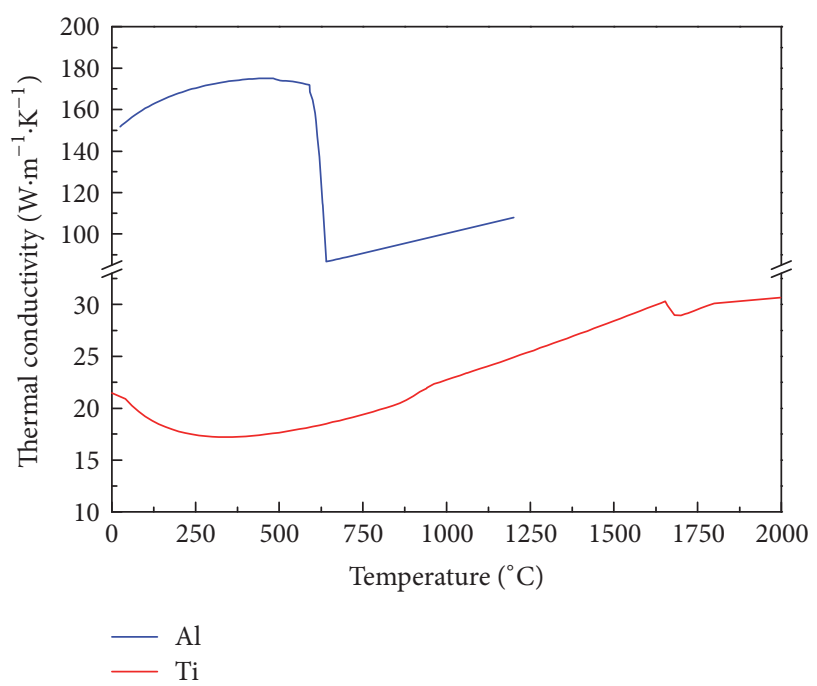

FIgure 2: Thermal conductivity of the Ti (Grade 2) and Al (AW 5754) alloy.

analysis. The finest mesh density along the weld line is $0.2 \mathrm{~mm}$. FEM model of a welded sample with the detail of generated mesh is shown in Figure 1. It consists of a total number of 79858 nodes and 68400 3D elements.

Thermophysical material properties of the $\mathrm{Ti}$ (Grade 2) and $\mathrm{Al}$ (AW 5754) alloys in the dependence on temperature computed using the JMatPro software [39] are plotted in Figures 2-4. Titanium Grade 2 represents commercially pure titanium (99.2\%) with the liquidus temperature of $T_{L}=$ $1660^{\circ} \mathrm{C}$. The equilibrium solidus and liquidus temperatures for the AW 5754 alloy were computed to be $600^{\circ} \mathrm{C}$ and $660^{\circ} \mathrm{C}$, respectively. The enthalpy of fusion was taken into account applying the method of modified specific heat [40].

The initial condition can be written in the following form:

$$
T(x, y, z, t=0)=T_{0}(x, y, z)
$$

where $T_{0}$ is the initial temperature of welded components, mostly equal to the ambient (room) temperature. The initial temperature of plates was supposed to be $20^{\circ} \mathrm{C}$.

The boundary condition of the 3rd kind is possible to exploit for the definition of welded plates cooling by 


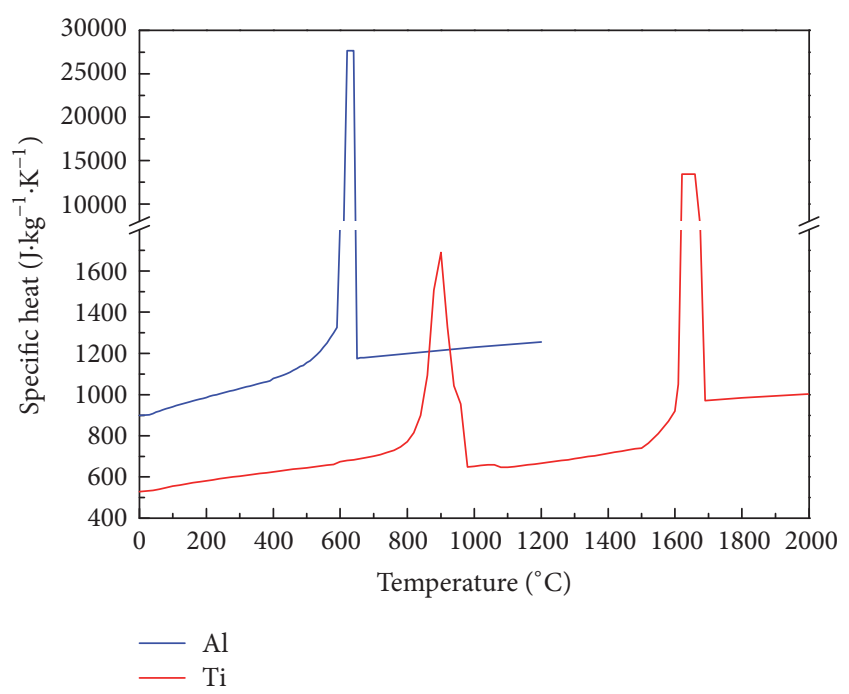

FIgURE 3: Specific heat of the Ti (Grade 2) and Al (AW 5754) alloy.

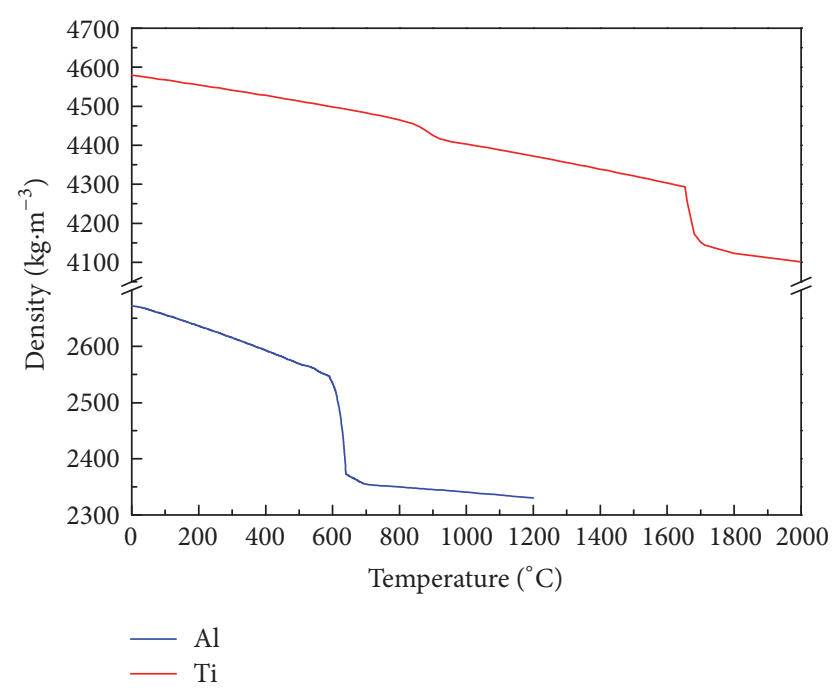

FIgure 4: Density of the Ti (Grade 2) and Al (AW 5754) alloy.

convection and radiation to the argon shielding gas and to the surrounding air:

$$
-\lambda \frac{\partial T}{\partial \mathbf{n}}=h\left(T_{w}-T_{f}\right)
$$

where $T_{w}$ is the sample surface temperature, $T_{f}$ is the surrounding fluid temperature, and $h$ represents the combine heat transfer coefficient given by the sum of convection heat transfer coefficient $h_{C}$ and radiation heat transfer coefficient $h_{R}$ :

$$
h=h_{C}+h_{R}=h_{C}+\frac{\varepsilon \sigma_{0}\left(T_{w}^{4}-T_{f}^{4}\right)}{T_{w}-T_{f}},
$$

where $\varepsilon$ is the emissivity and $\sigma_{0}$ is the Stefan-Boltzmann constant.

As it was mentioned, the heat input in fusion welding can be modeled by different methods including moving point or line heat sources and surface or volumetric heat sources. For the presented numerical simulation of laser welding of Ti-Al sheets, the Gaussian ellipsoidal volumetric heat source model (Figure 5) was applied [17, 41]. Using this model, it is possible to model sufficiently accurate various types of welding processes with different shape and depth of the weld pool [12]. The effective thermal power of a heat source is calculated according to the supposed volume of the weld pool. The Gaussian ellipsoidal volumetric heat source is defined by three parameters: the ellipsoid half-axes $a, b$, and $c$. The volumetric density of internal heat source $q_{v}\left[\mathrm{~W} \cdot \mathrm{m}^{-3}\right]$ is given by the following function [41]:

$$
\begin{aligned}
q_{v}(x, y, z) & =\frac{\Phi f(x, y, z)}{V} \\
& =\Phi \frac{6 \sqrt{3}}{a b c \pi^{3 / 2}} e^{-3 x^{2} / a^{2}} e^{-3 y^{2} / b^{2}} e^{-3 z^{2} / c^{2}}
\end{aligned}
$$

where $\Phi$ represents the effective laser power, $V=a \cdot b \cdot c$. $\pi^{3 / 2} /(6 \sqrt{3})$ is the volume of one half of the ellipsoid, and $f(x, y, z)=\exp \left(-3 x^{2} / a^{2}\right) \cdot \exp \left(-3 y^{2} / b^{2}\right) \cdot \exp \left(-3 z^{2} / c^{2}\right)$ is the Gaussian distribution function. Taking into account the welding speed $w\left[\mathrm{~m} \cdot \mathrm{s}^{-1}\right]$ and the distance $X[\mathrm{~m}]$ from the initial position of the source centre in the time $t=0 \mathrm{~s}$ (Figure 5(a)), it is possible to calculate the distribution of internal heat sources in an arbitrary time as illustrated in Figure 5(b).

For nonlinear transient thermal analyses in this study, the following parameters of the Gaussian volumetric heat source were applied: $a=1 \mathrm{~mm}, b=1 \mathrm{~mm}$, and $c=2.5 \mathrm{~mm}$. The laser power varied from $750 \mathrm{~W}$ to $950 \mathrm{~W}$ supposing that the efficiency is $63.5 \%$. The welding speed was set to the required value of $10 \mathrm{~mm} \cdot \mathrm{s}^{-1}$. In order to eliminate intermixing of both materials and thus the formation of hard and brittle intermetallic compounds, it was suggested to offset the laser beam on the titanium sheet side. The offset of laser beam to titanium side ranged from $50 \mu \mathrm{m}$ to $250 \mu \mathrm{m}$.

\section{Equipment for Experimental Laser Beam Welding}

For the preparation of experimental butt weld joints, the TruDisk 4002 disk laser [42] with the maximum power of $2 \mathrm{~kW}$, the wavelength of $1.03 \mu \mathrm{m}$, and the beam quality (BPP) of $8 \mathrm{~mm} \cdot \mathrm{mrad}$ was available. The laser beam can be transported to the BEO D70 focusing optics via laser light cable with the core diameter of $\varnothing 200 \mu \mathrm{m}$ or $\varnothing 400 \mu \mathrm{m}$. In case of application of the laser light cable with the core diameter of $\varnothing 400 \mu \mathrm{m}$ and the laser focusing on the top surface of components to be welded, the spot size of the laser beam is also $400 \mu \mathrm{m}$. The focusing optics are mounted on a 6-axis robot FANUC M-710iC/50 (Figure 6), enabling very accurate setting and control of welding parameters. Argon with the maximum flow rate of $30 \mathrm{l} \cdot \mathrm{min}^{-1}$ can be used for shielding the weld pool and/or the weld root. 


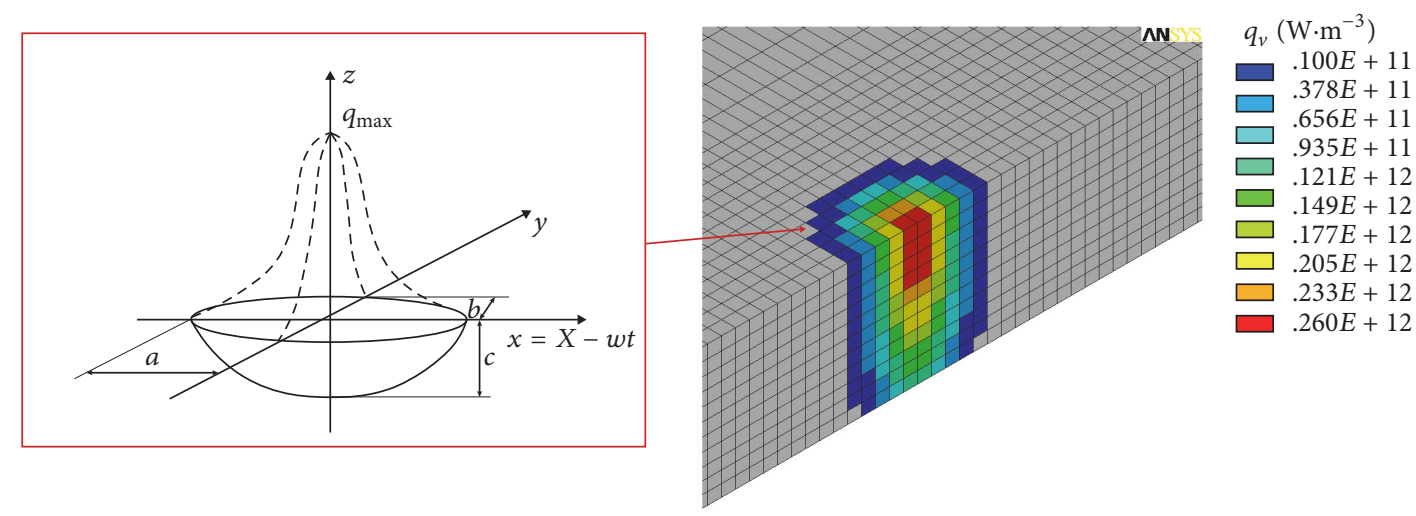

(a)

(b)

FIGURE 5: Gaussian ellipsoidal volumetric heat source: (a) the scheme with definition of parameters and (b) application of volumetric heat source to the FE model.
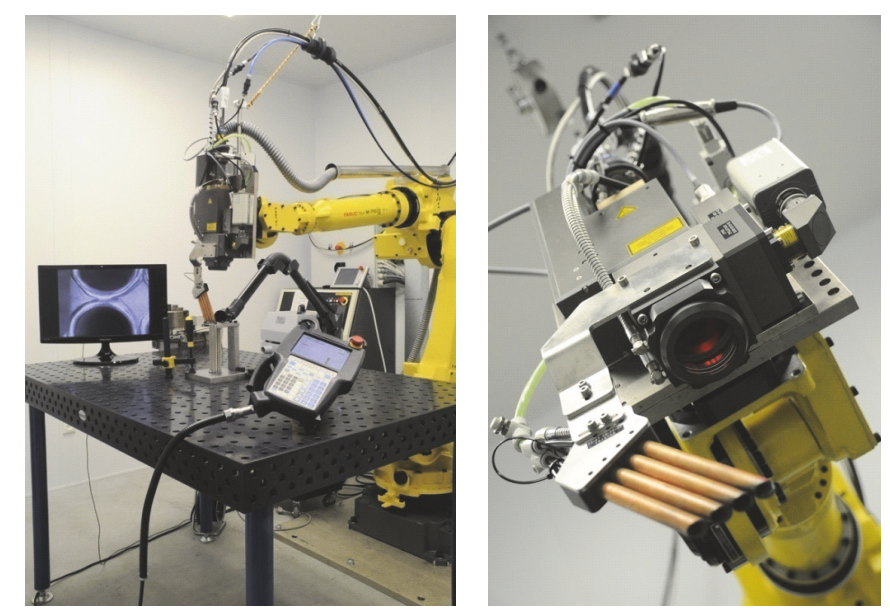

FIGURE 6: Laboratory of laser beam welding at the Faculty of Materials Science and Technology of STU in Trnava: (a) laser workplace with 6-axis robot FANUC M-710iC/50 and (b) detail of BEO D70 focusing optics.

\section{Results and Discussion}

In the first step, numerical simulation of laser beam welding of dissimilar Al-Ti sheets using the described simulation model was performed for the laser beam powers and the laser offsets given in Table 3. Based on the results of numerical simulation, parameters for the preparation of experimental weld joints were suggested. During experimental laser welding, the temperatures in selected points were measured and consequently applied for the verification of developed simulation model. Finally, the microstructure and the quality of produced weld joints were evaluated using light and scanning electron microscopy including EDX analysis, X-ray diffraction analysis, Vickers microhardness measurements, and tensile tests.

5.1. Results of Numerical Simulation. Numerical simulation of laser beam welding of dissimilar $\mathrm{Ti}-\mathrm{Al}$ sheets using the described simulation model was performed for the laser beam powers from $750 \mathrm{~W}$ to $950 \mathrm{~W}$ and the laser offsets to the Ti sheet from $50 \mu \mathrm{m}$ to $250 \mu \mathrm{m}$. For illustration, the computed temperature fields in chosen times for sample 3 (the laser power of $850 \mathrm{~W}$ and the laser offset of $250 \mu \mathrm{m}$ ) are shown in Figure 7. The influence of laser beam offset as well as the effect of differences in the material properties of $\mathrm{Ti}$ and $\mathrm{Al}$ alloys on the temperature distribution in welded sheets can be seen from this figure.

The time history of temperatures in the node $P$ located in the centre of a weld pool on the top surface of $\mathrm{Ti}$ plate (Figure 7) for different laser beam powers and the laser offset of $250 \mu \mathrm{m}$ is plotted in Figure 8. For the laser power of $750 \mathrm{~W}$, the maximum temperature in the node $P$ reaches the value of $1668^{\circ} \mathrm{C}$ which is only a few degrees above the titanium liquidus temperature. This result indicates that the laser power of $750 \mathrm{~W}$ will be insufficient for the formation of a weld joint with the desired quality. The maximum computed temperature during laser welding with the maximum considered laser power of $950 \mathrm{~W}$ is $1944^{\circ} \mathrm{C}$.

The influence of the laser offset on the maximum temperatures of the weld pool during laser welding is illustrated in Figure 9. The larger the laser offset, the higher the maximum 


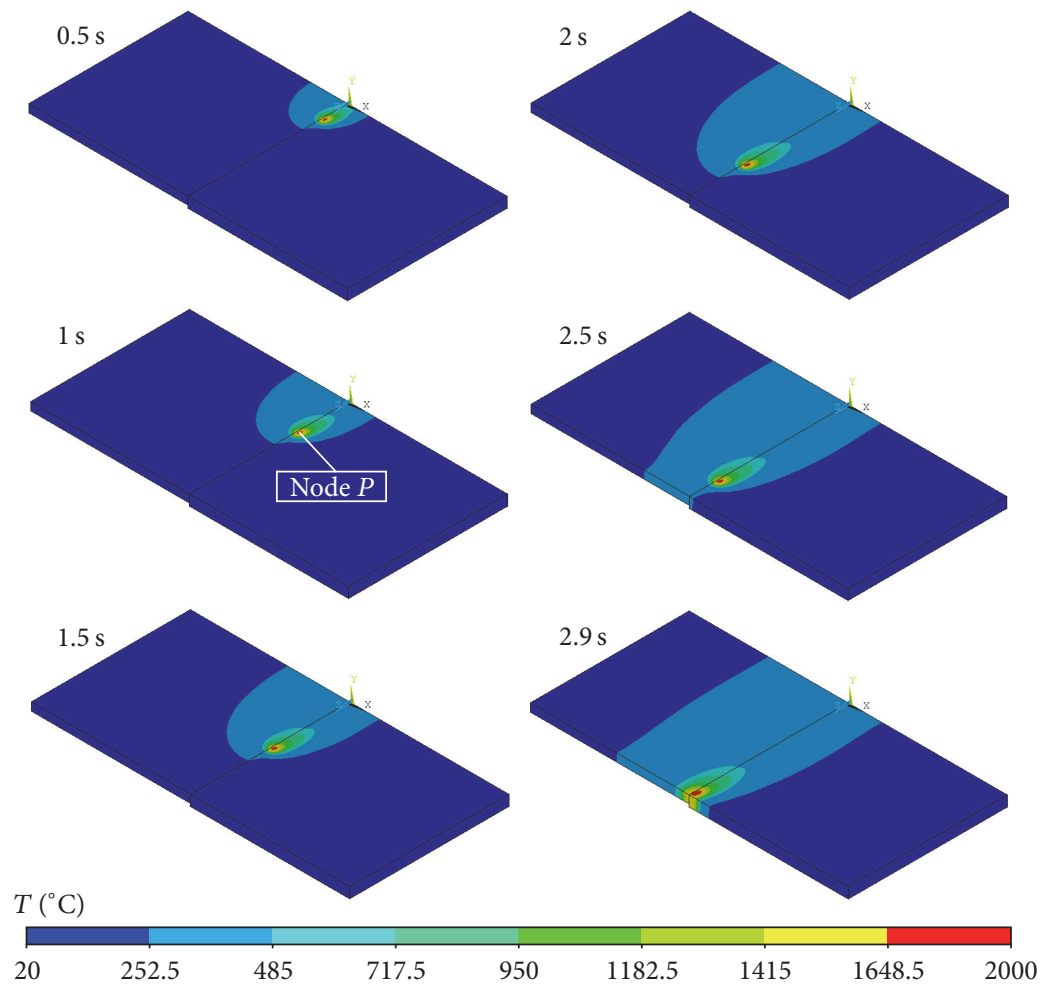

FIGURE 7: Temperature distribution in welded sheets in chosen times for sample 3 (the laser power of $850 \mathrm{~W}$ and the laser offset of $250 \mu \mathrm{m}$ ).

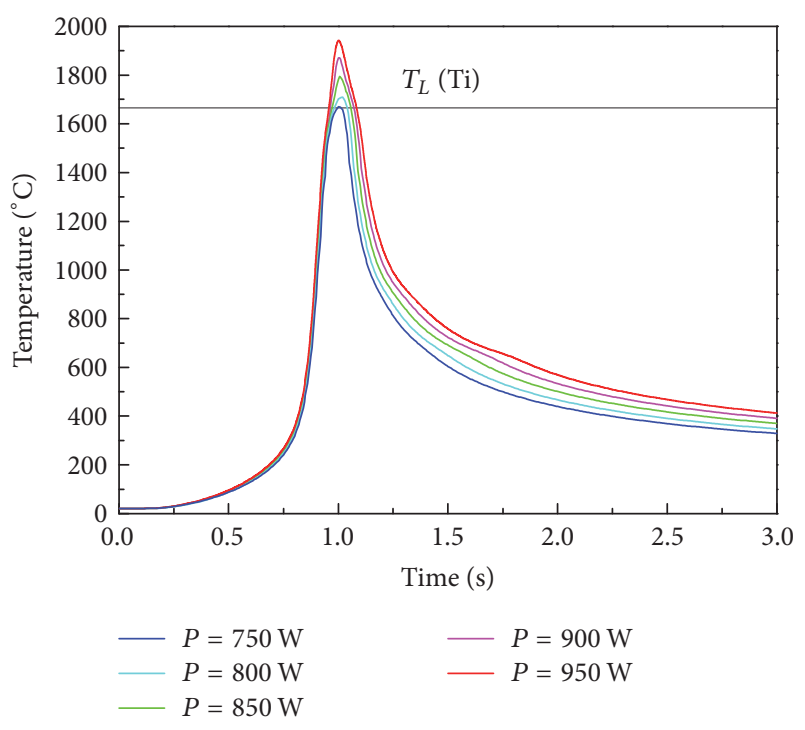

FIGURE 8: Time history of temperatures in the node $P$ located on the top surface in the centre of weld pool of Ti plate for different laser beam powers and the offset of $250 \mu \mathrm{m}$.

temperature of the weld pool, a consequence of the smaller thermal diffusivity of titanium in comparison to aluminium alloy. In case of smaller laser offset, the heat from the weld pool is dissipated faster to the AW 5754 alloy plate. This results in a smaller maximum temperature of the weld pool but on the other hand results in the higher temperature
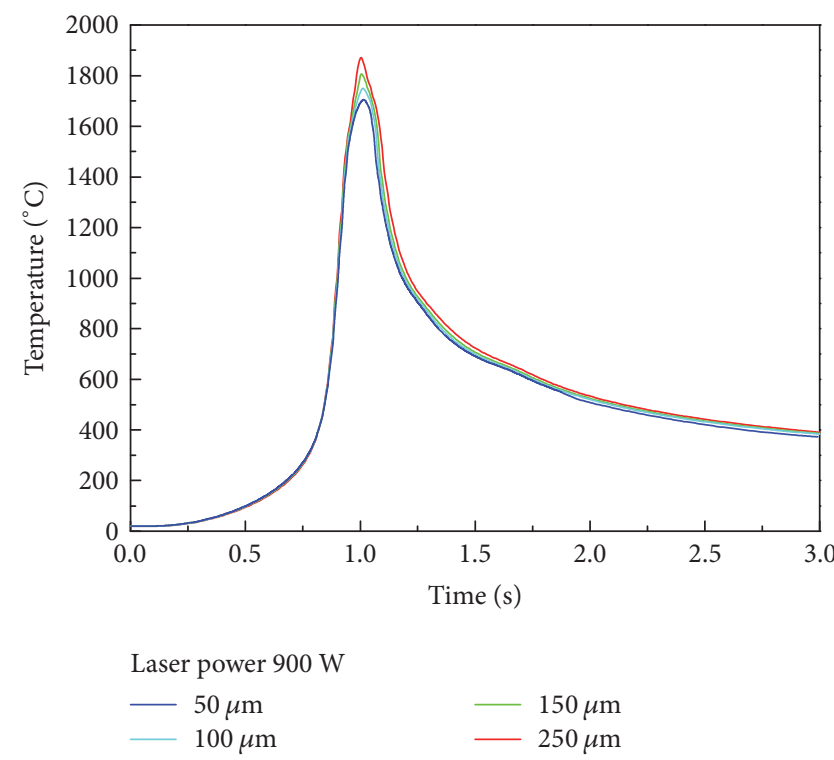

FIGURE 9: Influence of the laser offset on the time history of temperatures in the node $P$ for the laser power of $900 \mathrm{~W}$.

at the interface of welded Al-Ti plates. The dependence of temperatures on the distance from the weld centre for different laser offsets and the laser power of $850 \mathrm{~W}$ and $900 \mathrm{~W}$, respectively, is shown in Figure 10. The influence of laser power on the temperature distribution along the line perpendicular to the weld centre is documented in Figure 11. 


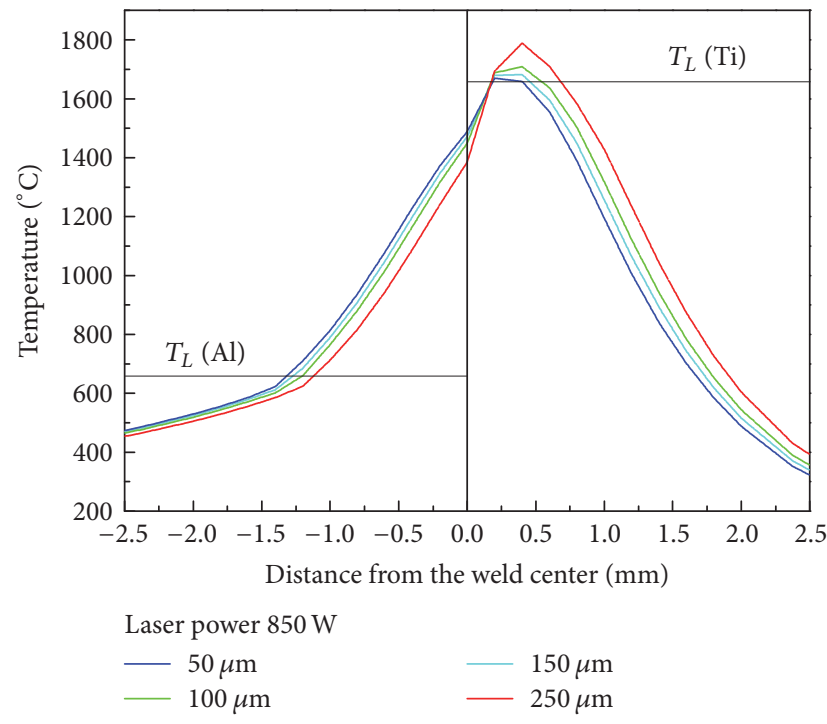

(a)

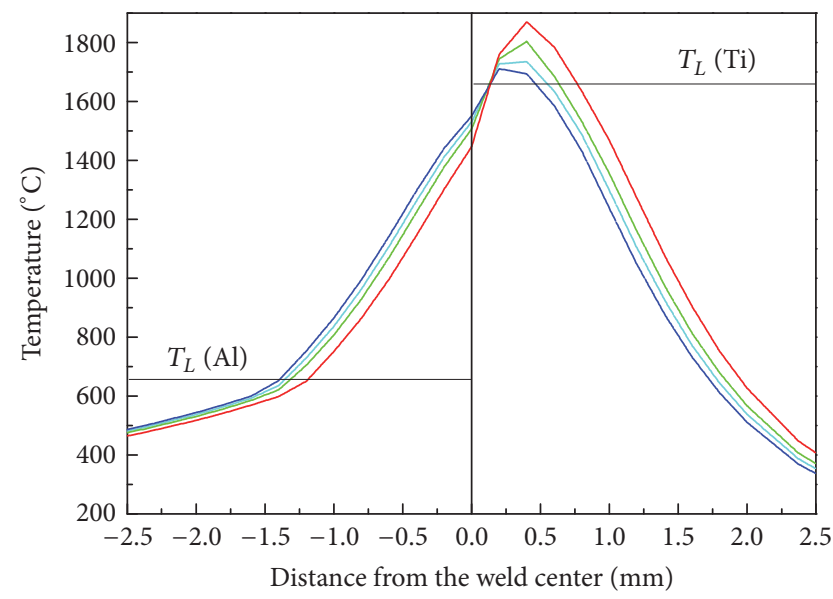

Laser power $900 \mathrm{~W}$

$\begin{array}{ll}-50 \mu \mathrm{m} & -150 \mu \mathrm{m} \\ -100 \mu \mathrm{m} & -250 \mu \mathrm{m}\end{array}$

(b)

Figure 10: The dependence of computed temperatures on the distance from the weld centre for different laser offsets and the laser power of (a) $850 \mathrm{~W}$ and (b) $900 \mathrm{~W}$.

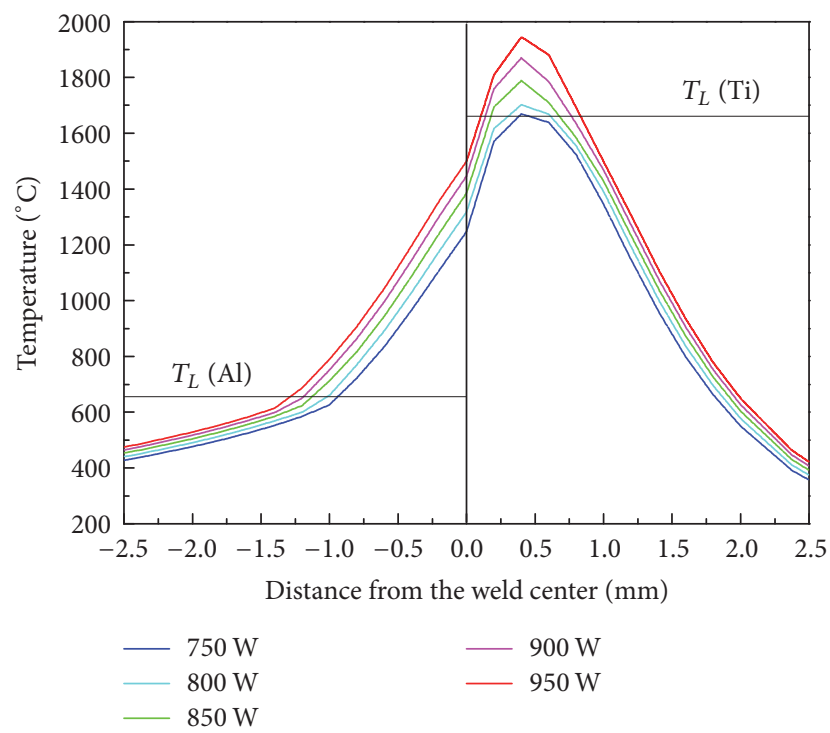

FIGURE 11: Dependence of computed temperatures on the distance from the weld centerline for different laser powers and the laser beam offset of $250 \mu \mathrm{m}$.

The increase in laser power leads to the enhancement of the maximum weld pool temperature and also leads to the increase of the interface temperature. A better idea about the temperature distribution in the welded sheets near the weld centre can be provided by Figures 12 and 13. In these figures, the temperature fields in perpendicular and longitudinal weld cross sections in the time of 1 second for chosen laser powers and considered laser offsets are illustrated. Figure 12 confirms the fact that the larger laser offset leads to the smaller interface temperature of the weld joint in the moment of laser beam passing. However, the maximum weld pool temperatures are

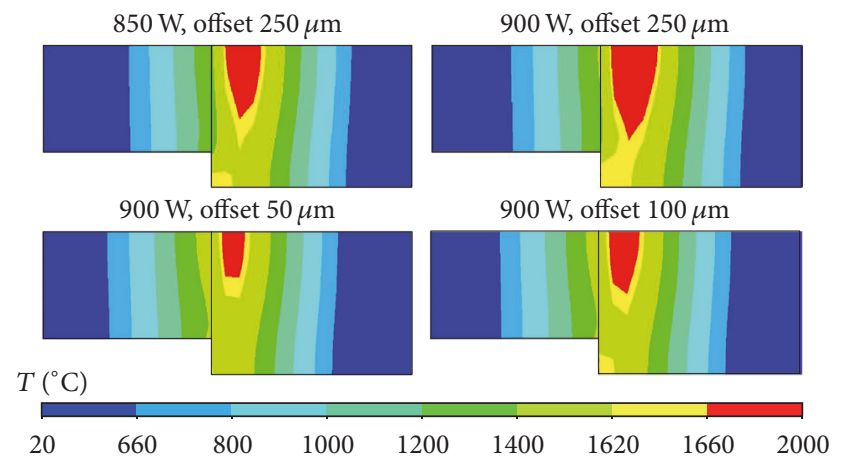

FIGURE 12: Temperature fields in the cross sections perpendicular to the Al-Ti weld centre through the node $P$ in the time of 1 second illustrating the effect of laser offset and the laser power.

higher for greater laser offsets. Thus, due to the mechanism of heat conduction and also convection in the weld pool, the maximum interface temperatures will achieve with some delay the higher values for the larger laser offsets, as can be seen from Figure 13. This figure also clearly demonstrates that the utilization of small laser offsets $(50 \mu \mathrm{m}$ and $100 \mu \mathrm{m})$ cannot provide suitable thermal conditions for the sound weld joint development as the temperatures of Ti plate are below the liquidus temperature for Ti Grade 2 .

Based on the results of numerical simulation of laser beam welding of Al-Ti sheets, it can be supposed that, for the laser beam offsets of $150 \mu \mathrm{m}$ and $250 \mu \mathrm{m}$, the Ti Grade 2 sheet will be melted across the whole thickness when the minimum laser power of $800 \mathrm{~W}$ is applied. In this reason, the following welding parameters were recommended for the experimental verification of simulation model and production of butt weld joints of Al-Ti sheets: 


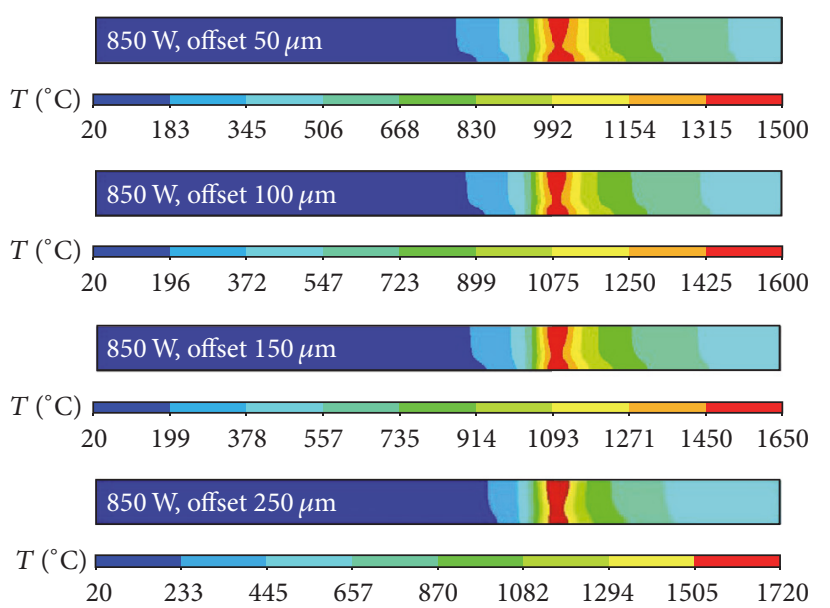

(a)

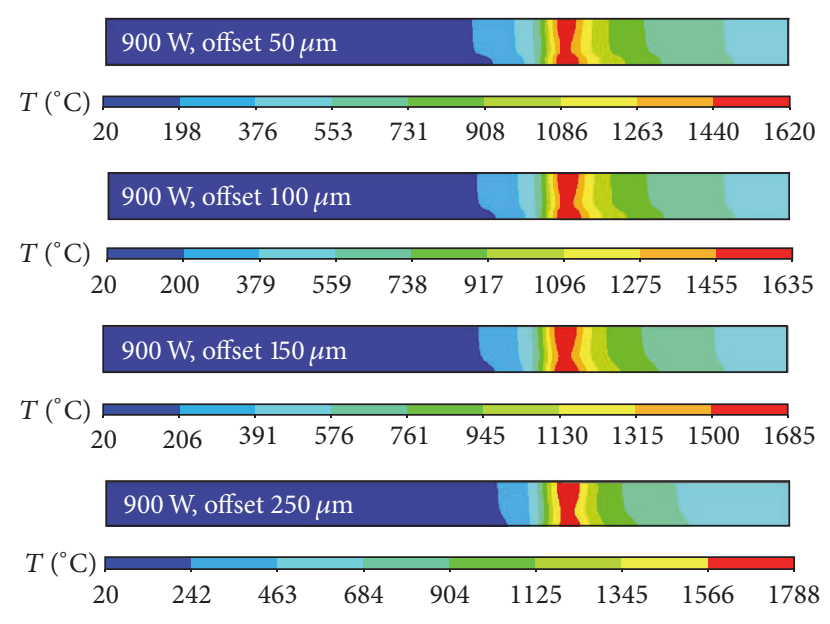

(b)

FIGURE 13: Temperature fields in the cross section along the plane of weld centre in the time of 1 second from the beginning of laser welding. (a) Laser power $850 \mathrm{~W}$; (b) laser power $900 \mathrm{~W}$.

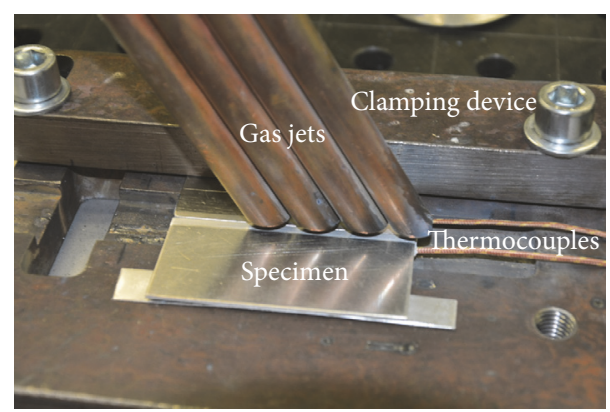

FIGURE 14: Specimen with thermocouples prepared for welding.

(i) The laser power from $800 \mathrm{~W}$ to $900 \mathrm{~W}$

(ii) The laser offset from $150 \mu \mathrm{m}$ to $250 \mu \mathrm{m}$

5.2. Verification of Simulation Model by Experimental Temperature Measurements. Experimental weld joints were prepared by the continuous wave TruDisk 4002 disk laser described in Section 3 using the laser light cable with the core diameter of $400 \mu \mathrm{m}$. Argon with the flow rate of $30 \mathrm{l} \cdot \mathrm{min}^{-1}$ was used as shielding gas. The laser beam was focused on the top surface of welded samples. During welding experiments, temperatures were measured by two thermocouples of the K-type located in the depth of $0.5 \mathrm{~mm}$ from the bottom side of samples and $3 \mathrm{~mm}$ from the weld centerline on the aluminium sheet and $4 \mathrm{~mm}$ on the titanium sheet. The specimen with thermocouples prepared for welding is shown in Figure 14. Figure 15 illustrates the bead and the root of butt weld joint prepared using the laser power of $800 \mathrm{~W}$ and the laser offset of $250 \mu \mathrm{m}$ (sample 2).

The time dependence of temperatures measured by thermocouples and computed in the nodes corresponding to the location of thermocouples is plotted in Figure 16. The maximum temperature measured by thermocouples in experiment 2 (sample 2) was $300.9^{\circ} \mathrm{C}$ on the $\mathrm{Ti}$ side and

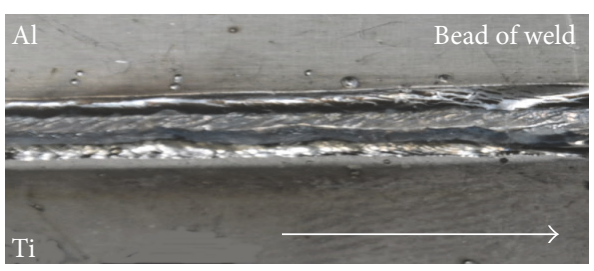

(a)

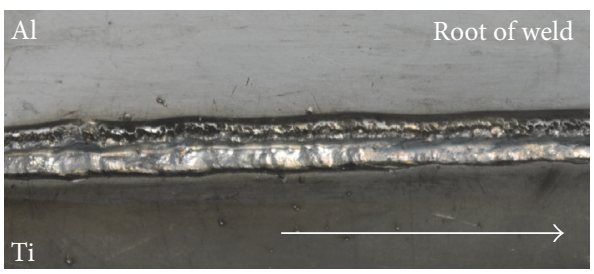

(b)

FIGURE 15: Appearance of the butt weld joint prepared with the laser power of $800 \mathrm{~W}$ and the laser offset of $250 \mu \mathrm{m}$ : (a) bead of weld and (b) root of weld.

$365.9^{\circ} \mathrm{C}$ on the $\mathrm{Al}$ side. The computed temperatures are slightly higher in comparison with experimentally measured temperatures. The temperature deviations can be caused by not pretty accurate setting of the heat source parameters or weld cooling by the shielding gas from the bottom side. Another reason can be also the fact that the thermal contact between $\mathrm{Al}$ and $\mathrm{Ti}$ plates was considered to be ideal in numerical simulations. If the plates are in solid state, the contact resistance definitely influences the temperatures at the interface of welded sheets. On the other hand, in the weld pool, the convection and intermixing of both welded materials contribute to the decrease of thermal gradients in molten zone. Nevertheless, it can be concluded that the results of numerical simulation are in a good agreement with the experimentally measured temperatures. 
TABLE 4: Results of point EDX analysis.

\begin{tabular}{|c|c|c|c|c|c|c|}
\hline Spectrum & $\mathrm{Mg}$ & $\mathrm{Al}$ & $\mathrm{Si}$ & $\mathrm{Ti}$ & $\mathrm{Mn}$ & $\mathrm{Fe}$ \\
\hline Spectrum 1 & & 22.07 & & 77.93 & & \\
\hline Spectrum 2 & & 25.57 & & 74.43 & & \\
\hline Spectrum 3 & & 32.86 & & 67.14 & & \\
\hline Spectrum 4 & 0.30 & 34.53 & & 64.67 & & 0.50 \\
\hline Spectrum 5 & & 62.98 & & 37.02 & & \\
\hline Spectrum 6 & & 34.72 & & 65.28 & & \\
\hline Spectrum 7 & 2.43 & 73.59 & 0.33 & 23.66 & & \\
\hline Spectrum 8 & 2.50 & 94.67 & & 0.60 & 0.23 & \\
\hline
\end{tabular}

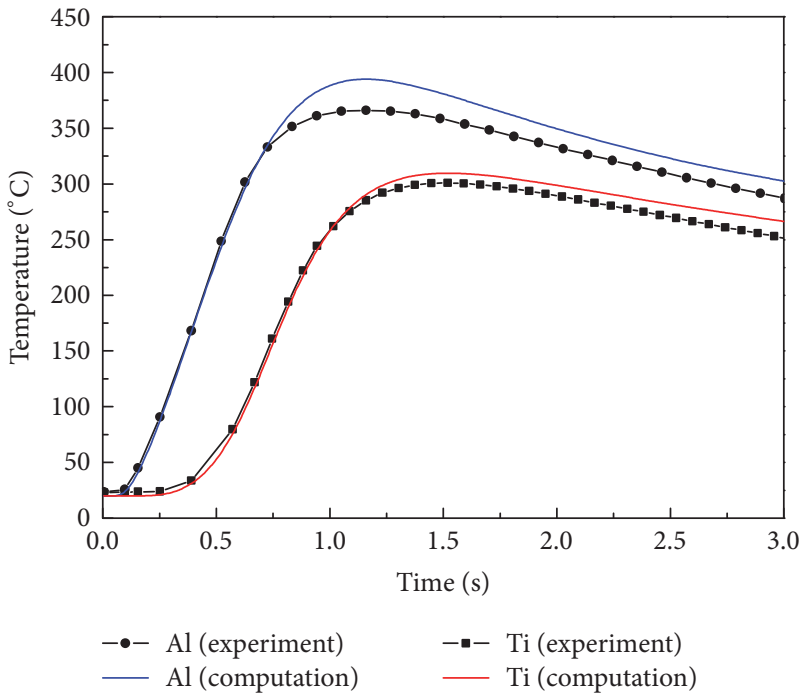

Figure 16: Time dependence of temperatures measured by thermocouples and computed in the nodes corresponding to the location of thermocouples (laser power of $800 \mathrm{~W}$; laser offset of $250 \mu \mathrm{m}$ ).

Figure 17 illustrates the influence of laser power on the computed temperatures in the nodes corresponding to the thermocouple location on the $\mathrm{Al}$ and $\mathrm{Ti}$ sides. The temperatures computed for the laser power of $750 \mathrm{~W}$ are below the experimentally recorded temperatures during the laser welding of Al-Ti plates with the laser power of $800 \mathrm{~W}$. This result also confirms that the simulation model is developed correctly.

5.3. Evaluation of the Quality of Produced Joints. After the laser welding, the samples were cut for the preparation of metallographic specimens. The macrostructure and microstructure of weld joints and the interface characteristic were investigated on the cross section of weld joints perpendicular to the direction of welding. After metallographic preparation of cross sections of welded joints, the specimens were etched with Keller's reagent with the chemical composition of $1.0 \mathrm{ml} \mathrm{HF}+1.5 \mathrm{ml} \mathrm{HCl}+2.5 \mathrm{ml} \mathrm{HNO}_{3}+$ $95 \mathrm{ml} \mathrm{H} \mathrm{H}_{2} \mathrm{O}$.

The light microscopy (NEOPHOT 32 light microscope) was used for the analysis of dissimilar Al-Ti weld joints. Figure 18(a) documents the macrostructure of the weld joint for sample 2. In the weld joint of Al-Ti dissimilar metals, different zones can be typically identified, that is, AW 5754 aluminium alloy, aluminium based weld metal, interface layer, titanium based weld metal, titanium heat-affected zone (HAZ), and titanium Grade 2 base metal.

Weld root concavity was observed on the aluminium alloy side. The microstructures at the interfaces of titanium Grade 2 and the heat-affected zone are shown in Figure 18(b). The microstructure of titanium Grade 2 consists of fine equiaxed $\alpha$ grains. Grain coarsening was observed in HAZ due to higher heat input used. The width of HAZ on titanium side reached the value of $1.085 \mathrm{~mm}$. This is also associated with the lower thermal conductivity of titanium. The microstructure of aluminium AW 5754 alloy and weld metal (WM) interface is illustrated in Figure 18(c). The microstructure of weld metal is quite different from the microstructure of original material. Columnar grains present in the weld metal are oriented towards the weld centre.

Figure 19 exhibits the microstructure and heterogeneous character of the weld metal for samples 3 and 4 . Zones with different chemical compositions can be seen in the microstructure. It is evident that intermixing of both metals (titanium Grade 2 and AW 5754 aluminium alloy) occurred resulting in the development of complex structures.

Electron microscopy was carried out in order to study the microstructure of produced weld joints in more detail. Scanning electron microscope JEOL 7600F fitted with EDX analyzer X-max $50 \mathrm{~mm}^{2}$ from Oxford Instruments was applied. The microstructure of aluminium alloy and titanium weld metal is depicted in Figure 20. The needle-shaped particles represent zones with the presence of titanium. This statement can be proven by the results of EDX analysis summarized in Table 4. The locations of point EDX analysis are designated in Figure 21. The large bright zones (Spectrums 1 to 3) are characterized by higher content of titanium. The results of EDX analysis indicate that the titanium content decreases in the direction to the aluminium side of the weld metal. Higher content of Al compared to Ti was documented in Spectrum 5. On the contrary, the dark zones are characterized by high content of aluminium. Aluminium content in Spectrum 8 is almost 95 wt.\%. Small amount of $\mathrm{Mg}$ was also detected.

Vickers microhardness measurements were performed in the weld interface zone on Buehler IndentaMet 1100 microhardness tester. The load of $100 \mathrm{~g}$ acting during $10 \mathrm{sec}$ 


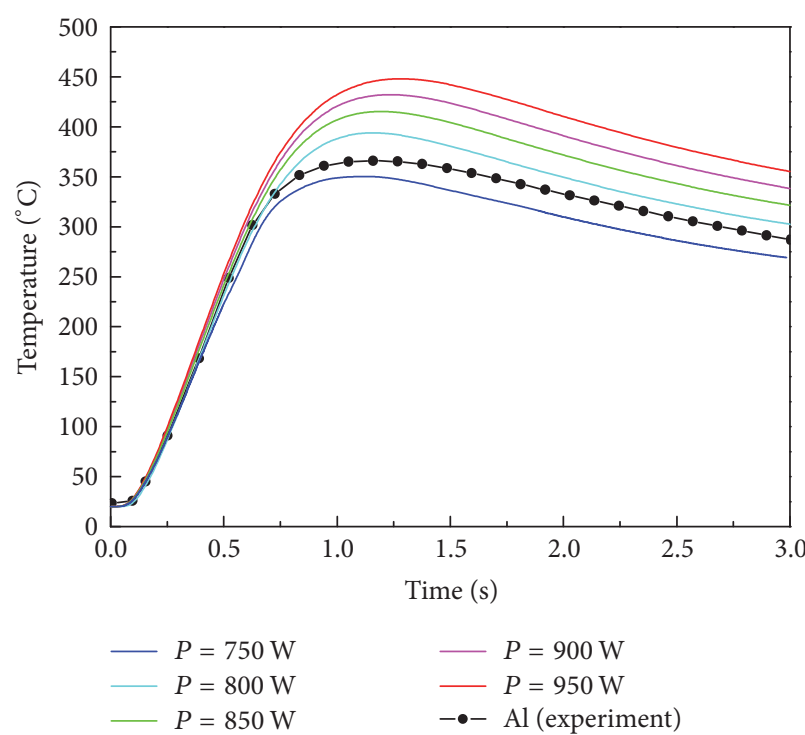

(a)

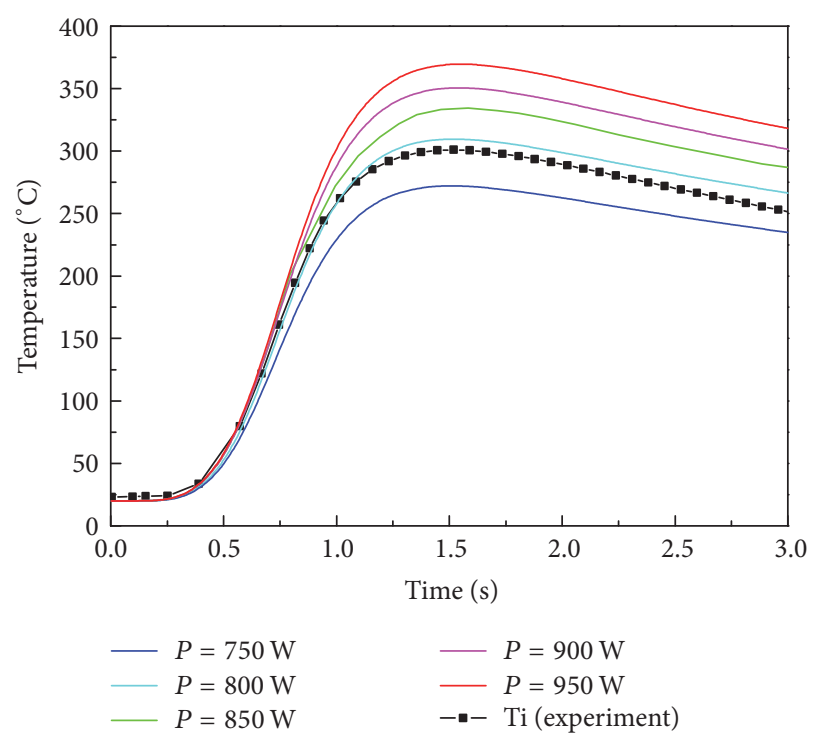

(b)

FIGURE 17: Influence of laser power on the computed temperatures in the nodes corresponding to the thermocouple location on the (a) Al side and (b) Ti side (laser offset of $250 \mu \mathrm{m}$ ).

was applied. The distance between individual indents was $200 \mu \mathrm{m}$.

Figure 22 shows the microhardness distribution across dissimilar Al-Ti metals weld joints for sample 3 and sample 4. The microhardness of titanium ranged from approximately 150 to $190 \mathrm{HV0.1}$. The microhardness increase was recorded towards weld metal. The maximum microhardness was measured in weld metal, reaching the values of 512.9 HV0.1 and 481.1 HV0.1 for sample 3 and sample 4, respectively. From the microhardness values measured, it can be concluded that the maximum microhardness found in weld metal is more than 2.5 times higher than that measured in titanium Grade 2. On other hand, the average microhardness of the weld metal at the aluminium side is similar to the microhardness of AW 5754 aluminium alloy (approximately 60 HV0.1).

The higher values of microhardness in the weld metal (in the intermixing zones) could be associated with high cooling rates during laser beam welding and the development of hard intermetallic compounds during rapid solidification of weld pool. The chemical composition measured in the zone close to the indent (Figure 23) is given in Table 5. Based on the titanium and aluminium binary diagram [43], microhardness measurements, and results of EDX analysis, the presence of hard and brittle intermetallic compounds of $\mathrm{TiAl}, \mathrm{Ti}_{3} \mathrm{Al}$, and $\mathrm{Al}_{3}$ Ti types can be supposed. This assumption was confirmed by the X-ray diffraction analysis (Figure 24). In addition to intermetallic compounds of $\mathrm{Al}_{3} \mathrm{Ti}$ and $\mathrm{AlTi}_{3}, \mathrm{Al}_{18} \mathrm{Mg}_{3} \mathrm{Ti}_{2}$ was recorded by $\mathrm{X}$-ray diffraction as well.

The tensile testing of prepared dissimilar Al-Ti welds was carried out at the room temperature using the LabTest 5.250 Sp1 tensile testing machine (max. loading force $250 \mathrm{kN}$ ) of LABORTECH Company. The influence of the laser power and laser offset on the tensile strength of weld joints was
TABLE 5: Chemical composition measured in Spectrums 1 to 3.

\begin{tabular}{lccc}
\hline Spectrum & $\mathrm{Mg}$ & $\mathrm{Al}$ & $\mathrm{Ti}$ \\
\hline Spectrum 1 & 0.68 & 51.66 & 47.67 \\
Spectrum 2 & & 30.90 & 69.10 \\
Spectrum 3 & & 52.69 & 47.31 \\
\hline
\end{tabular}

investigated. In all tensile tests, the fractures were observed in the weld metal.

The dependence of tensile strength (UTS) of weld joints on the laser power is given in Figure 25 (remaining welding parameters were constant: the welding speed of $10 \mathrm{~mm} \cdot \mathrm{s}^{-1}$, focal position was $0 \mathrm{~mm}$, and laser offset to titanium Grade 2 sheet was $250 \mu \mathrm{m}$ ). The maximum tensile strength was reached for the weld joint produced with the laser power of $800 \mathrm{~W}$. The measured tensile strength was at the level of $80 \mathrm{MPa}$. This highest tensile strength can be associated with the low heat input used for welding of dissimilar metals. The calculated linear heat input in this case was $80 \mathrm{~J} / \mathrm{mm}$. It resulted in the development of a narrow molten zone leading to elimination of the intermixing of both metals and thus the formation of hard and brittle intermetallic compounds. On the contrary, the increase in laser power to $850 \mathrm{~W}$ resulted in the decrease of UTS of weld joints to about $64 \mathrm{MPa}$. The calculated linear heat input was $85 \mathrm{~J} / \mathrm{mm}$ in this case. The further increase of laser power to $900 \mathrm{~W}$ and thus the increase of linear heat input to $90 \mathrm{~J} / \mathrm{mm}$ led to the higher production of IMC and reduction of tensile strength of welds.

The dependence of UTS of joints on the laser offset is plotted in Figure 26. The maximum tensile strength of $80 \mathrm{MPa}$ was attained for the weld joint produced with the laser offset of $250 \mu \mathrm{m}$. This can be also attributed to the reduced amount of hard and brittle IMC. The reduction of tensile strength was 


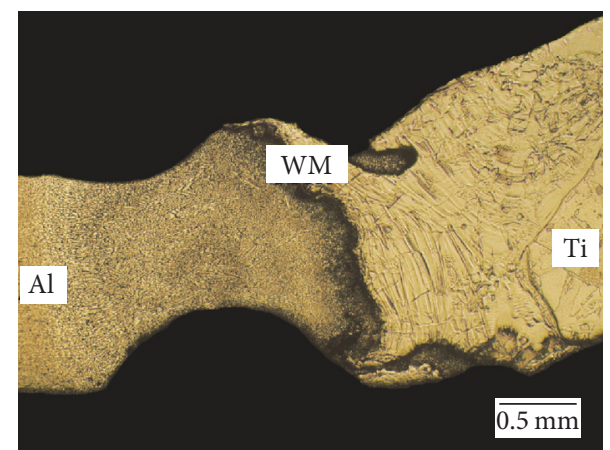

(a)

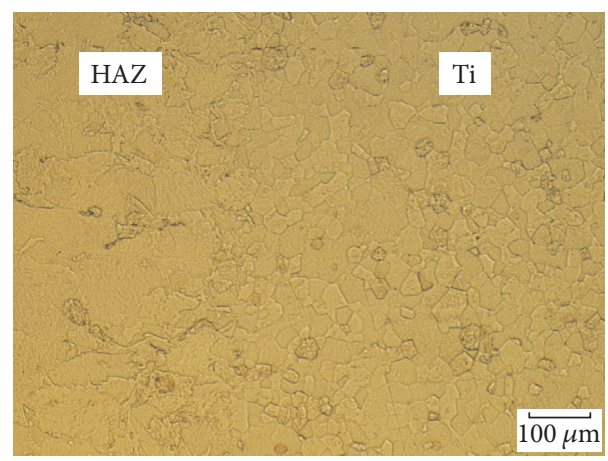

(b)

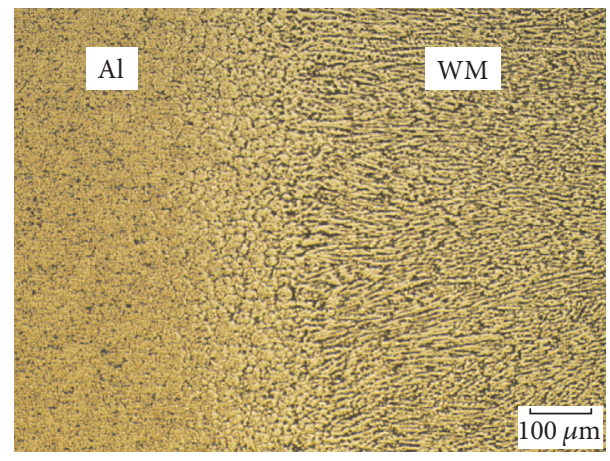

(c)

FIGURE 18: Macrostructure and microstructure of the weld joint (sample 2): (a) macrostructure of weld joint; (b) HAZ, titanium Grade 2 interface; (c) aluminium alloy, WM interface.

observed when the laser beam offset dropped to $150 \mu \mathrm{m}$. It can be supposed that in this case the intermixing of metals to be welded was higher. Tensile strength decreased to $32 \mathrm{MPa}$. The minimum tensile strength was recorded for the weld joints when the beam offset was only $100 \mu \mathrm{m}$.

The obtained results of tensile testing of Al-Ti dissimilar metals weld joints correspond to some published research in this field. Tomashchuk et al. [7] found that the linear tensile force measured during tensile testing of weld produced with beam offset towards Ti6Al4V titanium alloy led to the value of $120 \mathrm{~N} / \mathrm{mm}$. The division of this value by the original thickness of welded sheets $(2 \mathrm{~mm})$ provides the value of UTS at the level of $60 \mathrm{MPa}$. This value is approximate because it does not take into account the variation of thickness of the weld joint compared to the thickness of base materials. On the other hand, the authors observed the tensile strength of $120 \mathrm{MPa}$ when the laser beam was offset to the aluminium alloy [7]. This tendency was confirmed also by laser brazing of Ti6Al4V titanium alloy to A6061 aluminium alloy [44] or laser weld brazing of titanium Grade 2 to AW 5083 aluminium alloy using 5087 aluminium filler wire [45]. However, Casalino et al. [46] obtained the UTS of the dissimilar metals butt joints of AA5754 and T40 alloys as high as $191 \mathrm{MPa}$ using the laser power of $1.5 \mathrm{~kW}$, the welding speed of $1.80 \mathrm{~m} \cdot \mathrm{s}^{-1}$ (corresponding to linear heat input of $50 \mathrm{~J} / \mathrm{mm}$ ), and the beam offset of $0.75 \mathrm{~mm}$. In accordance with our findings, they proved significant influence of the linear energy input and also the laser beam offset on the mechanical properties of dissimilar metals weld joints. In case of the possibility to produce another shape of the weld joint, its UTS can be improved using the $\mathrm{V}$-groove as reported in [47] for weldingbrazing of Ti-6Al-4V titanium alloy to $5 \mathrm{~A} 06$ aluminium alloy or in [48] for joining of AA5754 aluminum alloy to T40 titanium with the use of Al-Si filler wires in both studies.

For this research, the butt joint of Al-Ti alloys together with the welding speed of $10 \mathrm{~mm} \cdot \mathrm{s}^{-1}$ was required. According to our investigation and published research, the mechanical properties of dissimilar Al-Ti weld joints can be improved by the enhancement of laser beam offset to the titanium side or by the use of laser weld brazing process applying Al based filler wire and setting the beam offset to the aluminium alloy side.

\section{Conclusions}

The possibility of producing butt joints of sheets from dissimilar metals (AW 5754 aluminium alloy and commercially pure titanium Grade 2) with different thicknesses using the disk laser welding was investigated.

Applying numerical simulation of the laser welding process in the program code ANSYS, the influence of the welding parameters on the temperature fields developed during the laser welding of dissimilar Al-Ti alloys was studied. For the fixed welding speed of $10 \mathrm{~mm} \cdot \mathrm{s}^{-1}$, the laser power was changed from $750 \mathrm{~W}$ to $950 \mathrm{~W}$. In order to eliminate intermixing of both welded materials and formation of brittle intermetallic compounds, the setting of laser beam offset towards the titanium side from $50 \mu \mathrm{m}$ to $250 \mu \mathrm{m}$ was tested. Based on the obtained results of numerical simulations, the following welding parameters were recommended for production of butt weld joints of Al-Ti sheets:

(i) The welding speed of $10 \mathrm{~mm} \cdot \mathrm{s}^{-1}$ (required)

(ii) The laser beam offset of $250 \mu \mathrm{m}$ (or more)

(iii) The laser power from $800 \mathrm{~W}$ to $850 \mathrm{~W}$

The quality of weld joints prepared using the TruDisk 4002 disk laser was evaluated by light and scanning electron microscopy, EDX analysis, X-ray diffraction, microhardness measurements, and the tensile tests. 


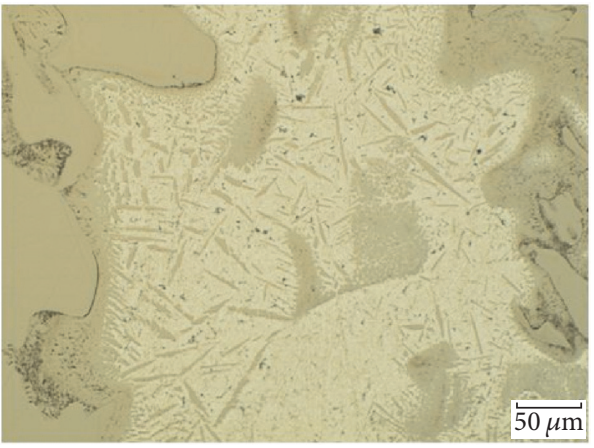

(a)

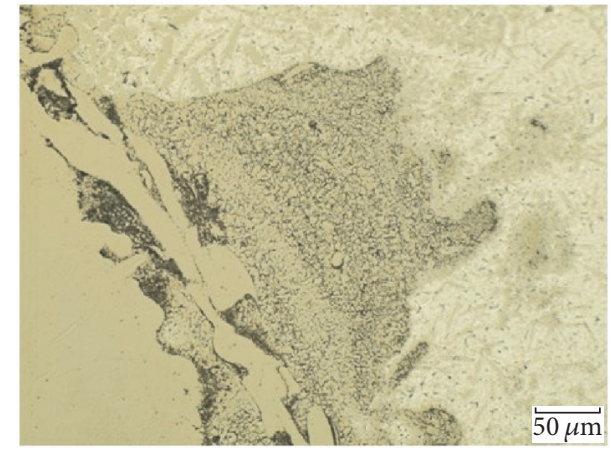

(b)

FIgURE 19: Microstructure of the weld metal for (a) sample 3 and (b) sample 4.

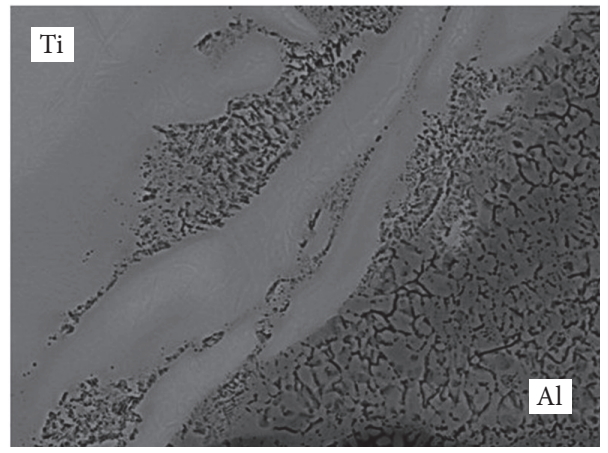

FIGURE 20: Microstructure of aluminium AW 5754 alloy and Ti Grade 2 weld metal.

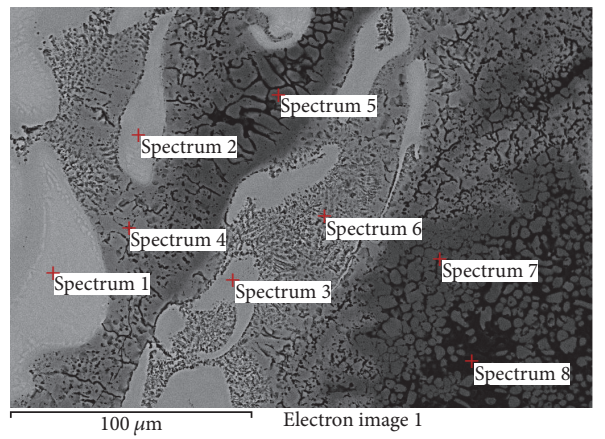

FIGURE 21: Location of point EDX analysis carried out in different zones of weld metal.

The following can be stated based on the attained results:

(i) The produced weld joints consist of different areas, namely, AW 5754 aluminium alloy, aluminium based weld metal, interface layer, titanium based weld metal, titanium HAZ, and titanium Grade 2 base metal.

(ii) Intermixing of titanium Grade 2 and aluminium alloy AW 5754 occurred at the interface of welded sheets, resulting in the development of hard and brittle intermetallic compounds of $\mathrm{Al}_{3} \mathrm{Ti}, \mathrm{Ti}_{3} \mathrm{Al}$, and $\mathrm{Al}_{18} \mathrm{Mg}_{3} \mathrm{Ti}_{2}$ types (confirmed by XRD).

(iii) The formation of hard and brittle IMC reduced with the increase of laser beam offset to the titanium side. (iv) The microhardness increased in the weld metal in comparison to the base metals (due to intermixing of both metals).

(v) The highest tensile strength of $80 \mathrm{MPa}$ was recorded for the weld joint prepared using the laser power of $800 \mathrm{~W}$ and laser beam offset of $250 \mu \mathrm{m}$ to the titanium Grade 2 sheet.

(vi) The tensile strength increased with decreasing the linear heat input and with enhanced laser beam offset to the titanium side as a result of elimination of the intermixing of welded metals and thus the development of hard and brittle intermetallic 


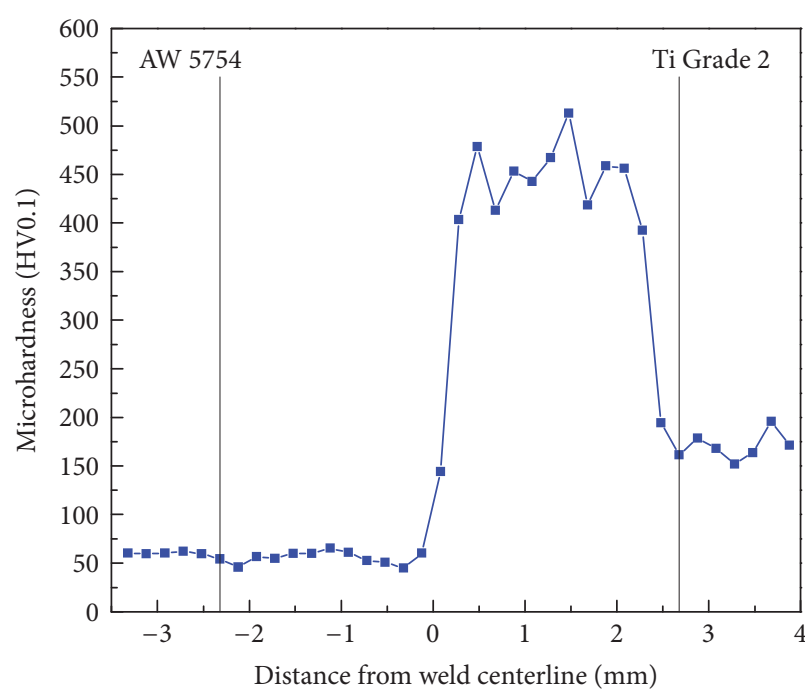

(a)

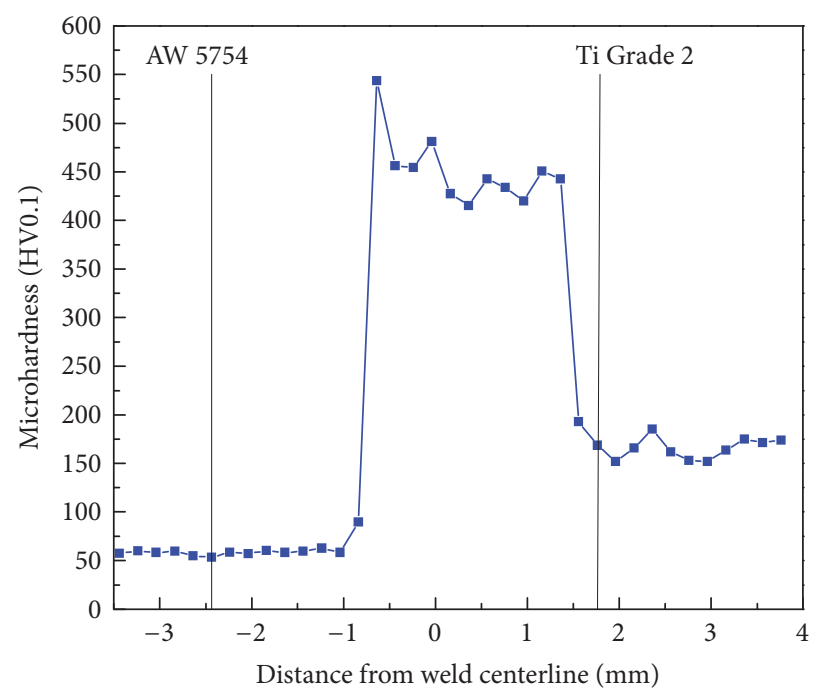

(b)

FIGURE 22: Results of microhardness measurements: the course of microhardness across AW 5754 aluminium alloy, weld metal, and titanium Grade 2 for (a) sample 3 and (b) sample 4.

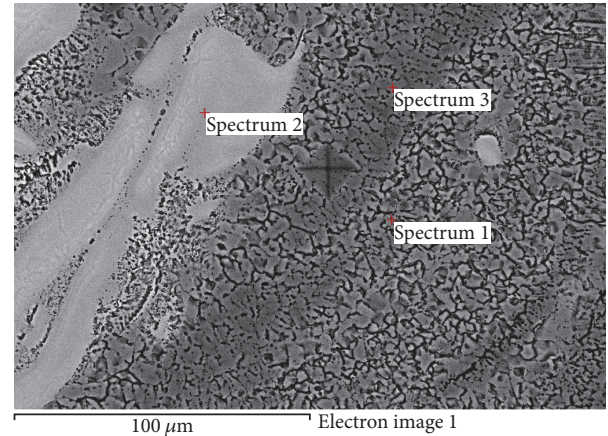

Figure 23: Indentation present in Al-Ti weld metal (sample 4).

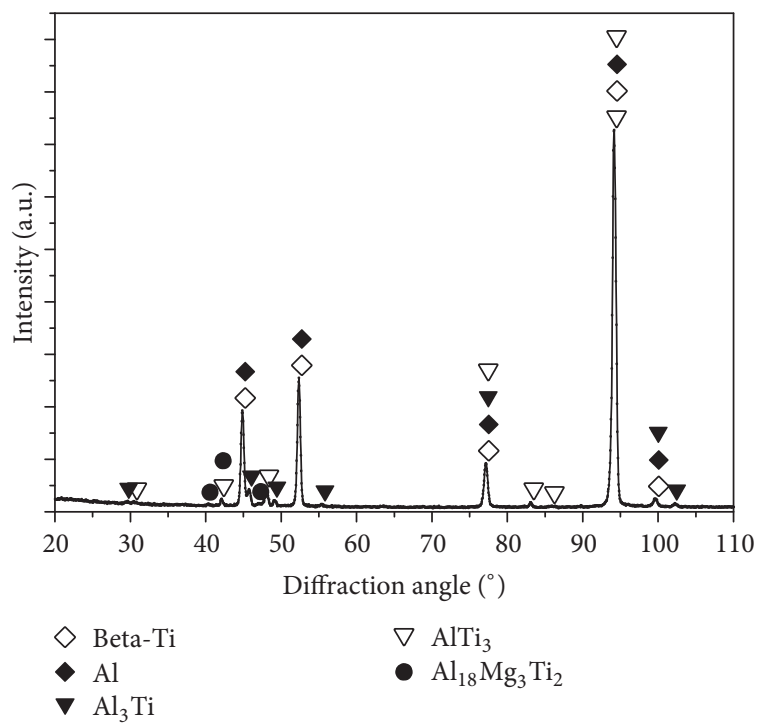

Figure 24: X-ray diffraction pattern of the weld metal.

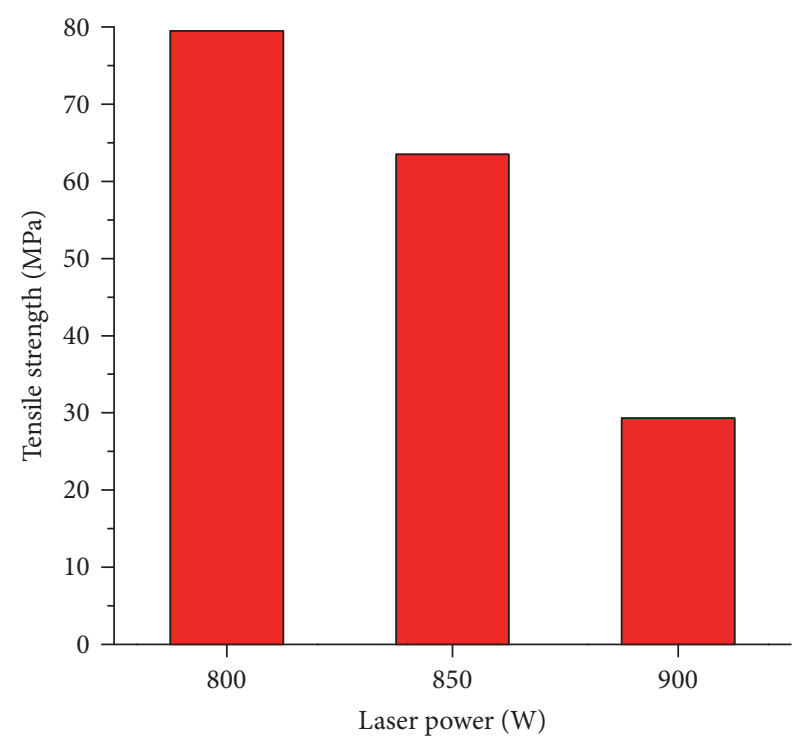

FIGURE 25: Dependence of tensile strength on laser power (laser beam offset of $250 \mu \mathrm{m})$.

compounds mostly responsible for the fracture of dissimilar metals weld joints.

(vii) Dissimilar Al-Ti butt weld joints with higher tensile strength prepared according to required condition (welding speed of $10 \mathrm{~mm} \cdot \mathrm{s}^{-1}$ ) could be in the next research produced with the laser offset larger than $250 \mu \mathrm{m}$ to the titanium sheet or by the laser weld brazing process using an aluminium based filler wire and setting the beam offset to the aluminium alloy side. 


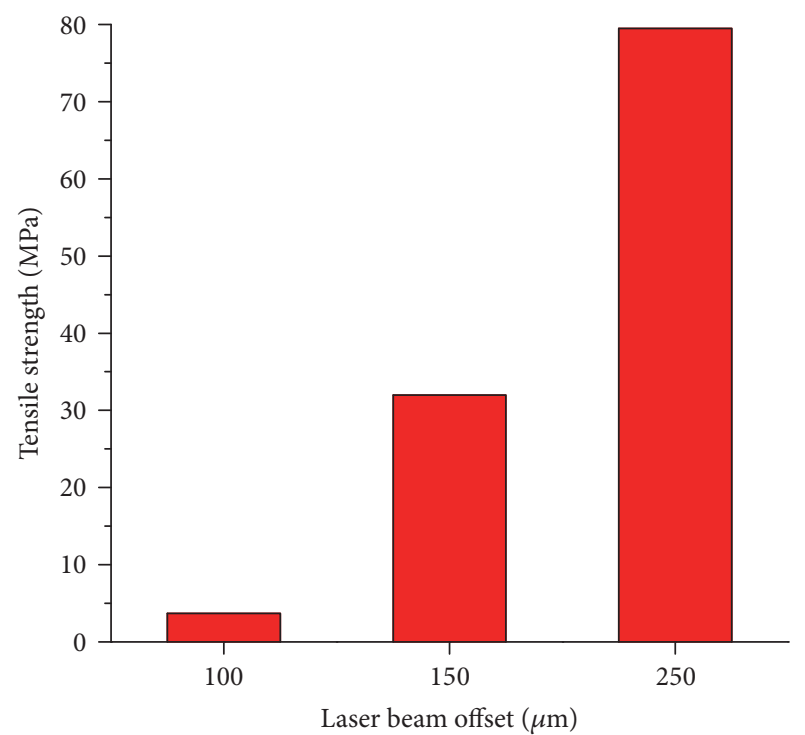

Figure 26: The dependence of tensile strength of joints on the laser offset (laser power of $800 \mathrm{~W}$ ).

\section{Conflicts of Interest}

The authors declare that they have no conflicts of interest.

\section{Acknowledgments}

The research has been supported by the Scientific Grant Agency of the Slovak Republic (VEGA) within the Project no. $1 / 1010 / 16$, the program to support excellent young research teams of the STU Bratislava (1347/PRO-MAT-ZVAR), and the Project ITMS 26220120048 under the Research \& Development Operational Programme funded by the ERDF.

\section{References}

[1] K. Martinsen, S. J. Hu, and B. E. Carlson, "Joining of dissimilar materials," CIRP Annals-Manufacturing Technology, vol. 64, no. 2, pp. 679-699, 2015.

[2] G. Pardal, S. Meco, A. Dunn et al., "Laser spot welding of laser textured steel to aluminium," Journal of Materials Processing Technology, vol. 241, pp. 24-35, 2017.

[3] R. Jiangwei, L. Yajiang, and F. Tao, "Microstructure characteristics in the interface zone of Ti/Al diffusion bonding," Materials Letters, vol. 56, no. 5, pp. 647-652, 2002.

[4] K.-M. Hong and Y. C. Shin, "Analysis of microstructure and mechanical properties change in laser welding of Ti6Al4V with a multiphysics prediction model," Journal of Materials Processing Technology, vol. 237, pp. 420-429, 2016.

[5] Z. Sun and J. C. Ion, "Laser welding of dissimilar metal combinations," Journal of Materials Science, vol. 30, no. 17, pp. 4205-4214, 1995.

[6] G. Casalino, P. Guglielmi, V. D. Lorusso, M. Mortello, P. Peyre, and D. Sorgente, "Laser offset welding of AZ31B magnesium alloy to 316 stainless steel," Journal of Materials Processing Technology, vol. 242, pp. 49-59, 2017.

[7] I. Tomashchuk, P. Sallamand, E. Cicala, P. Peyre, and D. Grevey, "Direct keyhole laser welding of aluminum alloy AA5754 to titanium alloy Ti6Al4V," Journal of Materials Processing Technology, vol. 217, pp. 96-104, 2015.

[8] Z. Ma, W. Zhao, J. Yan, and D. Li, "Interfacial reaction of intermetallic compounds of ultrasonic-assisted brazed joints between dissimilar alloys of Ti-6Al-4V and Al-4Cu-1Mg," Ultrasonics Sonochemistry, vol. 18, no. 5, pp. 1062-1067, 2011.

[9] X. Chen, R. Xie, Z. Lai, L. Liu, G. Zou, and J. Yan, "Ultrasonicassisted brazing of Al-Ti dissimilar alloy by a filler metal with a large semi-solid temperature range," Materials and Design, vol. 95, pp. 296-305, 2016.

[10] S. A. Tsirkas, P. Papanikos, and T. Kermanidis, "Numerical simulation of the laser welding process in butt-joint specimens," Journal of Materials Processing Technology, vol. 134, no. 1, pp. 5969, 2003.

[11] F. Boitout, D. Dry, and Y. Gooroochurn, Transient Simulation of Welding Processes, ESI Group, 2004.

[12] A. P. Mackwood and R. C. Craferb, "Thermal modelling of laser welding and related processes: a literature review," Optics \& Laser Technology, vol. 37, pp. 99-115, 2005.

[13] L.-E. Lindgren, "Numerical modelling of welding," Computer Methods in Applied Mechanics and Engineering, vol. 195, no. 4849, pp. 6710-6736, 2006.

[14] A. G. Olabi and G. Casalino, "Mathematical modeling of weld phenomena, part 1: finite-element modeling," Comprehensive Materials Processing, vol. 6, pp. 101-109, 2014.

[15] G. Casalino and M. Mortello, "Modeling and experimental analysis of fiber laser offset welding of Al-Ti butt joints," International Journal of Advanced Manufacturing Technology, vol. 83, no. 1-4, pp. 89-98, 2016.

[16] G. Casalino, M. Mortello, and P. Peyre, "FEM Analysis of Fiber Laser Welding of Titanium and Aluminum," in Proceedings of the 48th CIRP International Conference on Manufacturing Systems (CIRP CMS '15), pp. 992-997, Isle of Ischia, Italy, June 2015.

[17] E. Babalová and M. Behúlová, "Numerical simulation of temperature fields by welding of Ti-Al alloys applying volumetric heat source," Advanced Materials Research, vol. 887-888, pp. 1280-1283, 2014.

[18] Y. Ai, P. Jiang, X. Shao et al., "The prediction of the whole weld in fiber laser keyhole welding based on numerical simulation," Applied Thermal Engineering, vol. 113, pp. 980-993, 2017.

[19] D. Radaj, Heat Effects of Welding, Springer, Berlin, Germany, 1992.

[20] Z. Saternus, "Computer methods for determination of deformations in welded closed profiles," Procedia Engineering, vol. 177, pp. 188-195, 2017.

[21] A. Franco, L. Romoli, and A. Musacchio, "Modelling for predicting seam geometry in laser beam welding of stainless steel," International Journal of Thermal Sciences, vol. 79, pp. 194205, 2014.

[22] J. Rahman Chukkan, M. Vasudevan, S. Muthukumaran, R. Ravi Kumar, and N. Chandrasekhar, "Simulation of laser butt welding of AISI 316L stainless steel sheet using various heat sources and experimental validation," Journal of Materials Processing Technology, vol. 219, pp. 48-59, 2015.

[23] R. Spina, L. Tricarico, G. Basile, and T. Sibillano, "Thermomechanical modeling of laser welding of AA5083 sheets," Journal of Materials Processing Technology, vol. 191, no. 1-3, pp. 215-219, 2007.

[24] N. S. Shanmugam, G. Buvanashekaran, K. Sankaranarayanasamy, and S. Ramesh Kumar, "A transient finite element 
simulation of the temperature and bead profiles of T-joint laser welds," Materials and Design, vol. 31, no. 9, pp. 4528-4542, 2010.

[25] L. J. Zhang, J. X. Zhang, A. Gumenyuk, M. Rethmeier, and S. J. $\mathrm{Na}$, "Numerical simulation of full penetration laser welding of thick steel plate with high power high brightness laser," Journal of Materials Processing Technology, vol. 214, no. 8, pp. 1710-1720, 2014.

[26] J. Goldak, A. Chakravarti, and M. Bibby, "A new finite element model for welding heat sources," Metallurgical Transactions B, vol. 15, no. 2, pp. 299-305, 1984.

[27] C. S. Wu, G. Wang, and Y. M. Zhang, "A new heat source model for keyhole plasma arc welding in FEM analysis of the temperature profile," Welding Journal, vol. 85, pp. 284-291, 2006.

[28] N. S. Shanmugam, G. Buvanashekaran, K. Sankaranarayanasamy, and K. Manonmani, "Some studies on temperature profiles in AISI 304 stainless steel sheet during laser beam welding using FE simulation," International Journal of Advanced Manufacturing Technology, vol. 43, no. 1-2, pp. 78-94, 2009.

[29] N. Siva Shanmugam, G. Buvanashekaran, and K. Sankaranarayanasamy, "Some studies on weld bead geometries for laser spot welding process using finite element analysis," Materials and Design, vol. 34, pp. 412-426, 2012.

[30] S.-J. Na and W.-I. Cho, "Developments in modelling and simulation of laser and hybrid laser welding," in Handbook of Laser Welding Technologies, S. Katayama, Ed., Electronic and Optical Materials, pp. 522-560, Woodhead Publishing, Cambridge, UK, 2013.

[31] M. Zain-Ul-Abdein, D. Nélias, J. F. Jullien, and D. Deloison, "Thermo-mechanical analysis of laser beam welding of thin plate with complex boundary conditions," International Journal of Material Forming, vol. 1, supplement 1, pp. 1063-1066, 2008.

[32] M. Dal and R. Fabbro, "An overview of the state of art in laser welding simulation," Optics and Laser Technology, vol. 78, pp. 2-14, 2016.

[33] M. Zain-ul-Abdein, D. Nelias, J.-F. Jullien, and D. Deloison, "Prediction of laser beam welding-induced distortions and residual stresses by numerical simulation for aeronautic application," Journal of Materials Processing Technology, vol. 209, no. 6, pp. 2907-2917, 2009.

[34] L.-E. Lindgren, "Finite element modeling and simulation of welding part 1: increased complexity," Journal of Thermal Stresses, vol. 24, no. 2, pp. 141-192, 2001.

[35] B. Souloumiac, F. Boitout, and J.-M. Bergheau, "A new local global approach for the modelling of welded steel component distortions," Mathematical Modelling of Weld Phenomena, vol. 6, pp. 573-590, 2002.

[36] D. Deng, "FEM prediction of welding residual stress and distortion in carbon steel considering phase transformation effects," Materials and Design, vol. 30, no. 2, pp. 359-366, 2009.

[37] P. F. Incropera and D. P. De Witt, Fundamentals of Heat and Mass Transfer, Wiley and Sons, New York, NY, USA, 1996.

[38] ANSYS Mechanical ADPL Theory Reference. ANSYS, Inc. Release 15.0. SAS IP, Inc., 2015.

[39] JMatPro Help, release 6.1, Sente Software Ltd., 2012.

[40] H. Hu and S. A. Argyropoulos, "Mathematical modelling of solidification and melting: a review," Modelling and Simulation in Materials Science and Engineering, vol. 4, no. 4, pp. 371-396, 1996.

[41] E. Friedman, "Thermomechanical analysis of the welding process using the finite element method," Journal of Pressure Vessel Technology, vol. 97, no. 3, pp. 206-213, 1975.
[42] 2017, http://www.mtf.stuba.sk/english/development-and-eustructural-funds/centers-of-excellence/center-of-excellence-5axis-machining.html?page_id=10353.

[43] E. Illeková, P. Švec, and D. Janičkovič, "Influence of the processing on the ordering process in the Al-Ti binary system with composition close to $\mathrm{Al}_{3}$ Ti," Journal of Physics: Conference Series, vol. 144, no. 1, 2009.

[44] Z. Song, K. Nakata, A. Wu, and J. Liao, "Interfacial microstructure and mechanical property of Ti6Al4V/A6061 dissimilar joint by direct laser brazing without filler metal and groove," Materials Science and Engineering A, vol. 560, pp. 111-120, 2013.

[45] M. Sahul, M. Sahul, M. Vyskoč, L'. Čaplovič, and M. Pašák, “Disk laser weld brazing of AW5083 aluminum alloy with titanium grade 2," Journal of Materials Engineering and Performance, vol. 26, no. 3, pp. 1346-1357, 2017.

[46] G. Casalino, M. Mortello, and P. Peyre, "Yb-YAG laser offset welding of AA5754 and T40 butt joint," Journal of Materials Processing Technology, vol. 223, pp. 139-149, 2015.

[47] S. Chen, L. Li, Y. Chen, J. Dai, and J. Huang, "Improving interfacial reaction nonhomogeneity during laser weldingbrazing aluminum to titanium," Materials and Design, vol. 32, no. 8-9, pp. 4408-4416, 2011.

[48] I. Tomashchuk, P. Sallamand, A. Méasson, E. Cicala, M. Duband, and P. Peyre, "Aluminum to titanium laser weldingbrazing in V-shaped groove," Journal of Materials Processing Technology, vol. 245, pp. 24-36, 2017. 

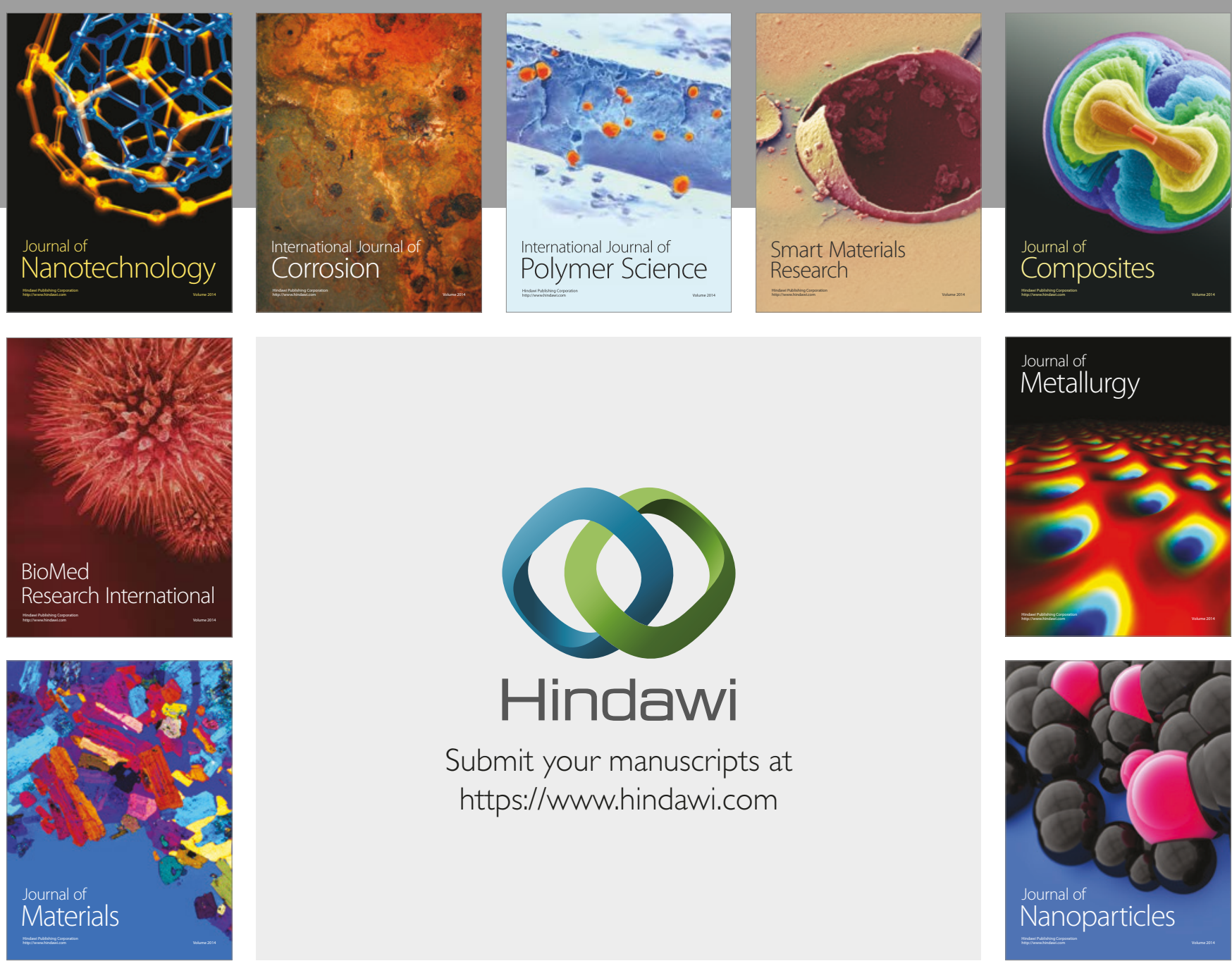

\section{Hindawi}

Submit your manuscripts at

https://www.hindawi.com
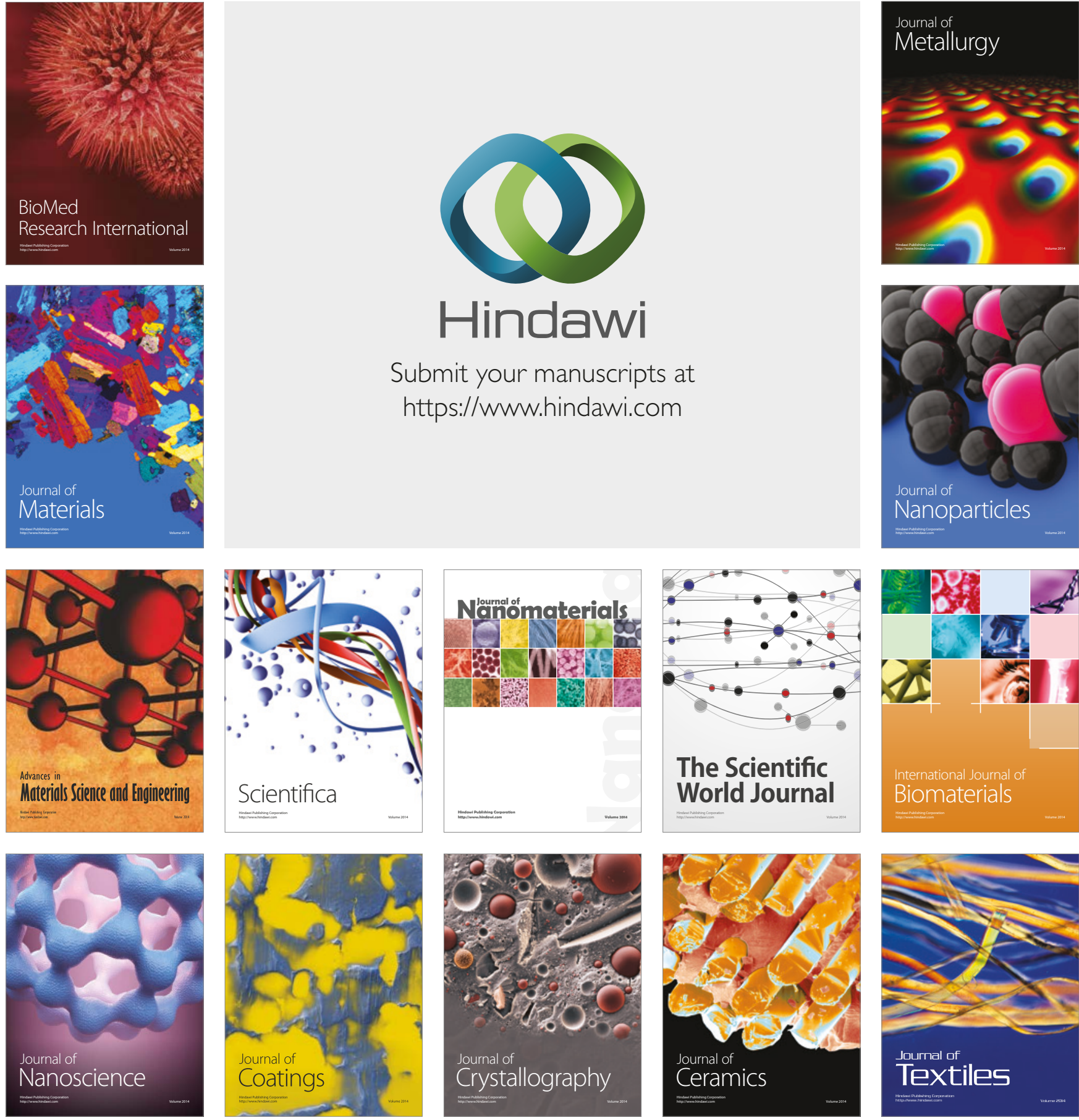

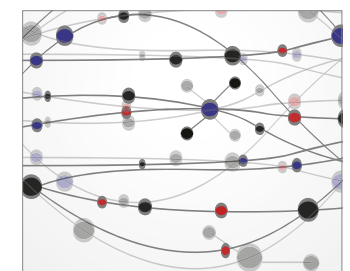

The Scientific World Journal
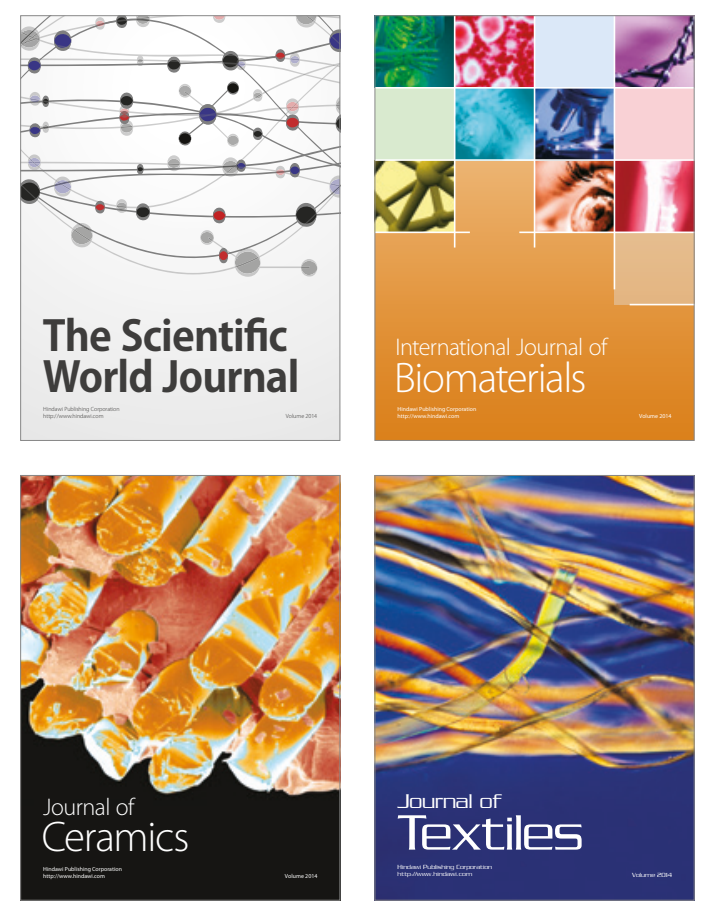